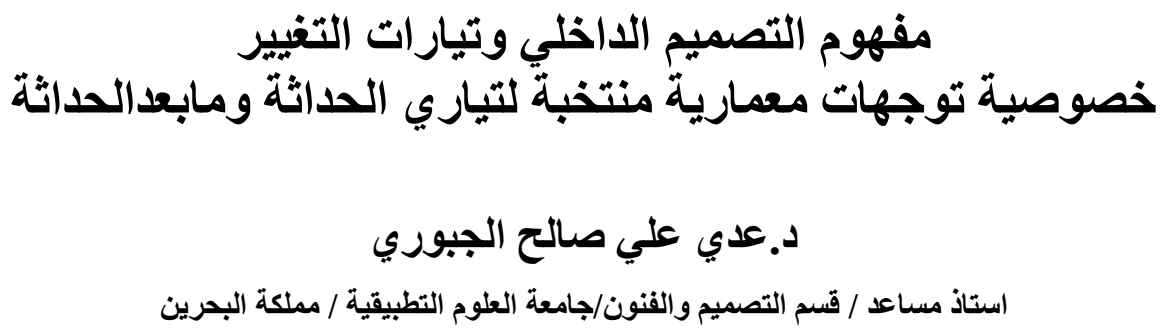

الخلاصة

يعد التصميم الداخلي من المفاهيم التي رافقت النظرية والممارسة المعمارية، حيث شكل التصميم التورئ التاخلي مظهرا

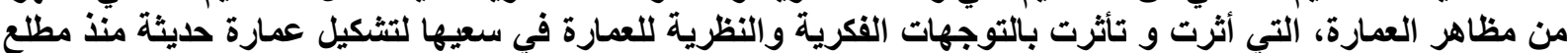

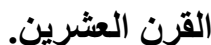

يناقث البحث التطور التأريخي لمفهوم التصميم الداخلي في الفترة التي تثكلت فيها حركة الحداثة وما بعد الحداثة.

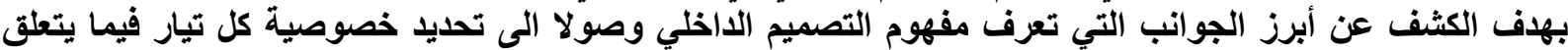

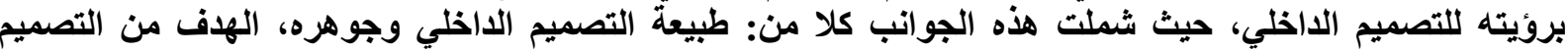

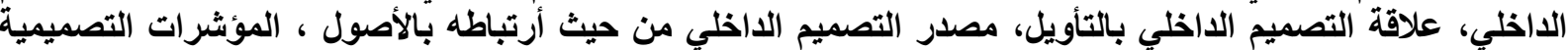
ل لعناصر التصميم الداخلي. كلمات دالة: التصميم الألئ،الداخل،الفضاء الداخل .

\title{
The concept of interior design and the changing movements Privacy elected of architectural movements of modern and postmodern
}

\author{
Dr. Oday Ali Al-Juboori \\ Assistant Professor - Department Of Design \& Arts - University Of Application Sciences -Kingdom Of \\ Bahrain
}

\begin{abstract}
Interior design is considered as a concept that accompanied the theory and practice of architecture. It is represented as a form of manifestation of Architecture, which influenced and affected by the intellectual trends and theory of architecture in their quest for the formation of modern architecture since the beginning of the twentieth century.

This paper discusses the historical concept development of interior design in the period, in which modernism and postmodernism was formed. The aim of this paper to detect the most prominent aspects that define the concept of interior design, and down to determine the particularity of each movement with respect to the interior design vision. These aspects were: the nature of the interior design and essence, the goal of the design procedure,the relationship of interior design with interpretation, its sources, and its design determinants.
\end{abstract}

Keywords: interior design, interior, interior space. 
شهوت الفترة التاريخية الممتدة بين عام 1850 و عام 1980 و لادة عدد من التوجهات التي دعت الى التغيير و أسست

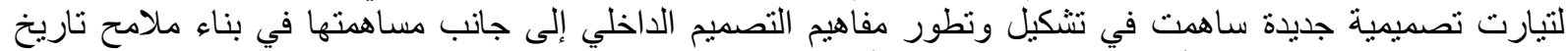

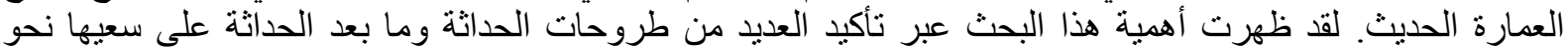

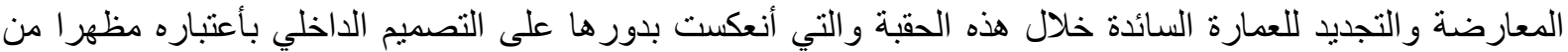

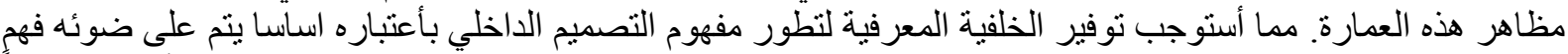

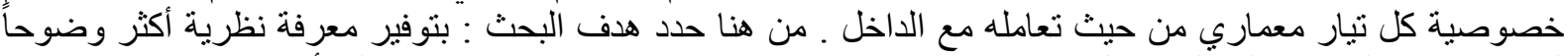

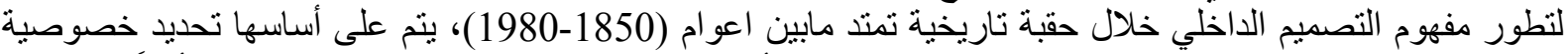

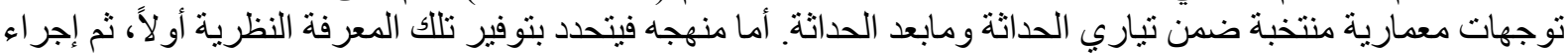

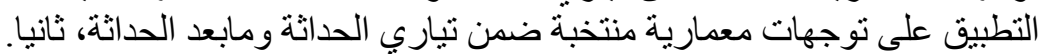

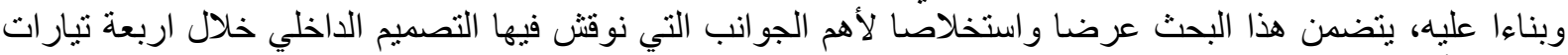

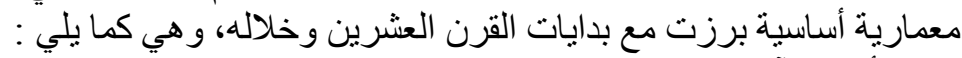

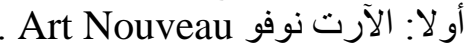

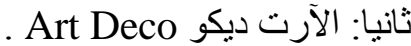

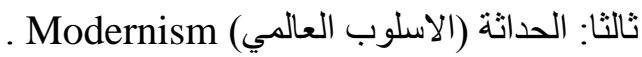
رابعا: ما بعد الحداثة Post-Modernism

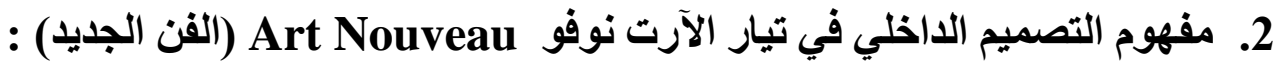

عُرف هذا التيار بتسميات مختلفة ضمن البلدان التي ظهر فيها، ففي بلجيكا والمانيا عرف بـ بـ "طراز الثباب البهاب

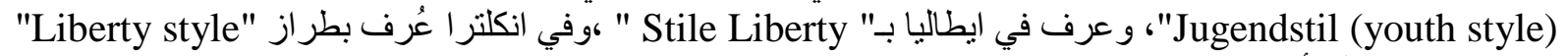

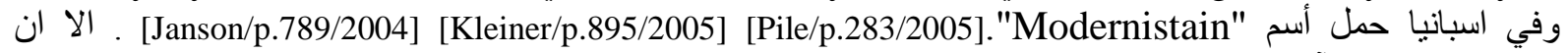

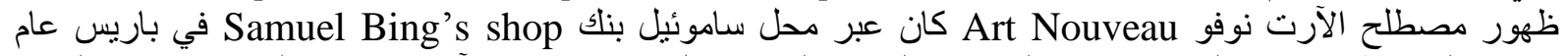

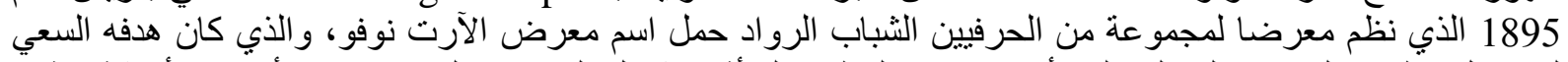

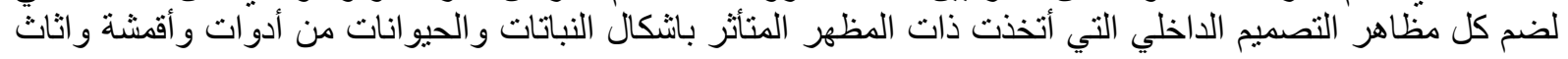

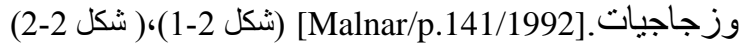

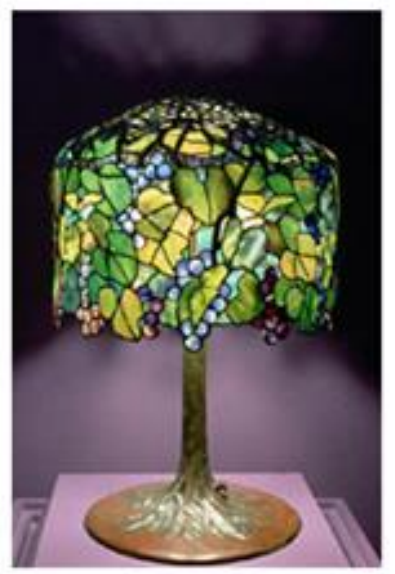

Louis comfort tiffany (3-2) نك

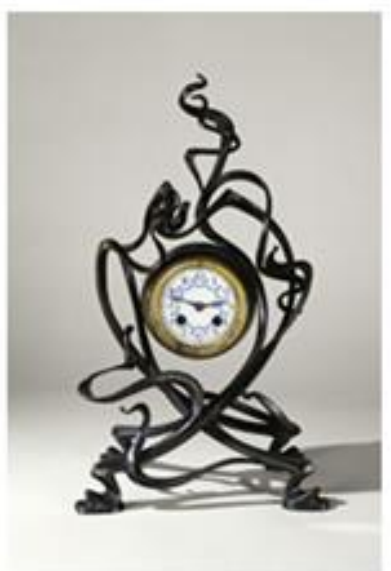

Emile Galle,1895 (2-2) Mackmurdo,1882 (1-2) نكل

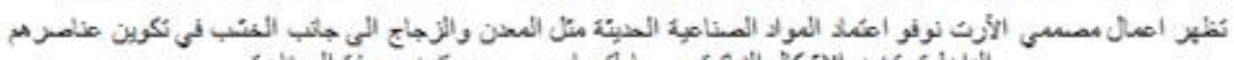

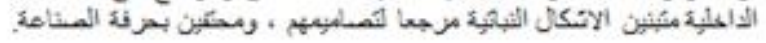

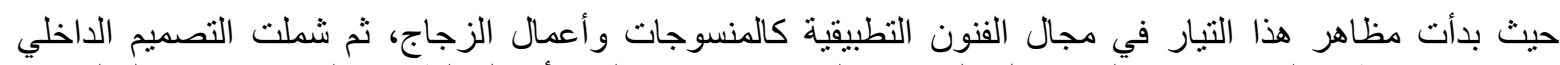

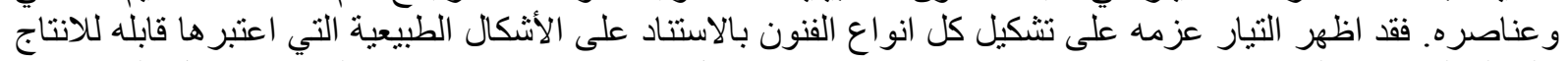

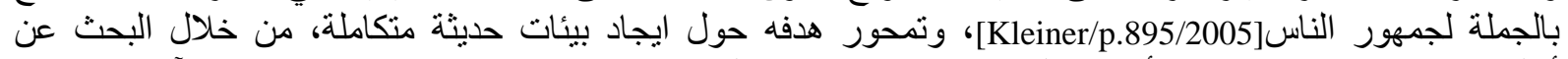

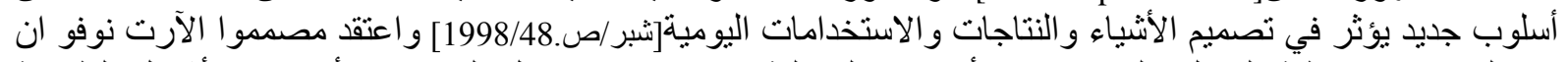

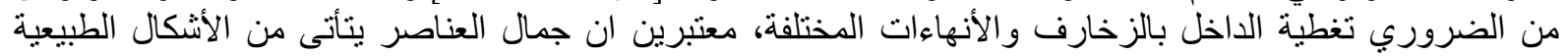


و البساطة و الحرفة الجيدة [Kilmer/p.65/2005]، وهو ما ترك أثره وبصماته على التصميم الداخلي ومجالاته اليومية. من

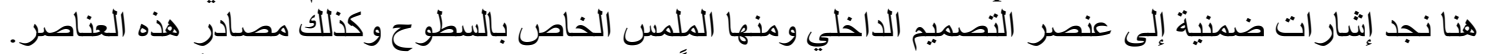

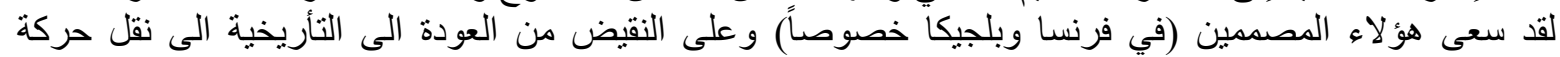

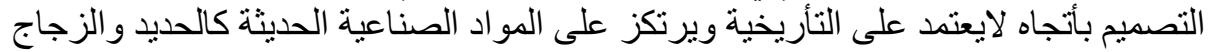

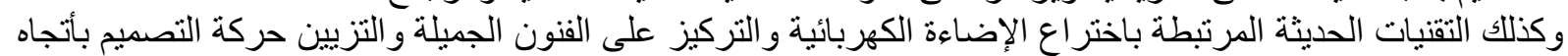

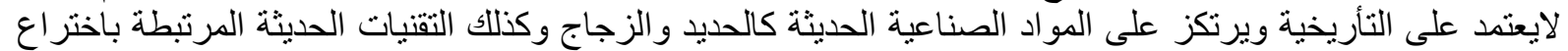

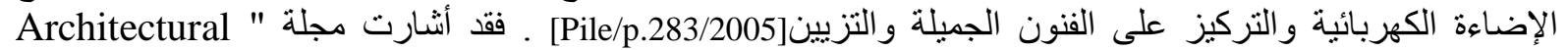

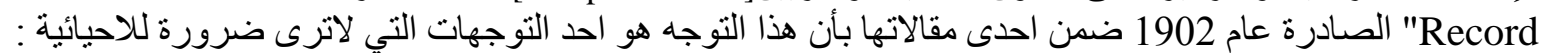

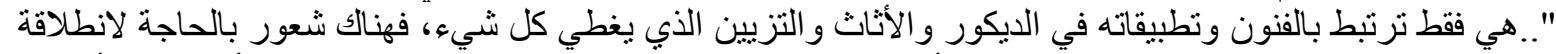

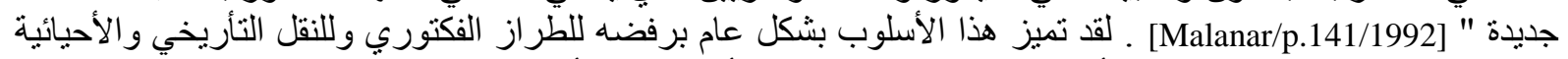

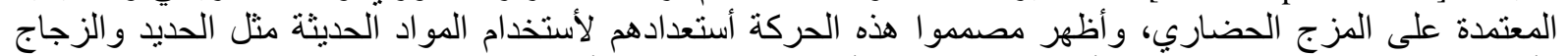

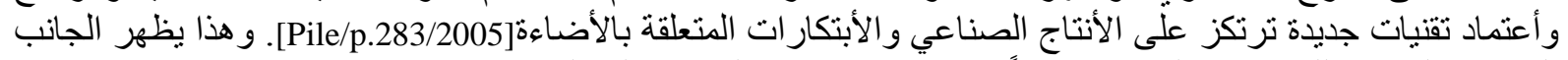

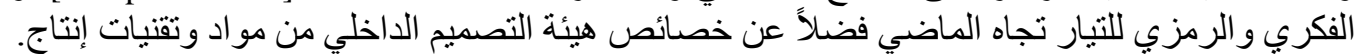

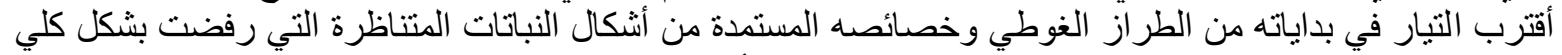

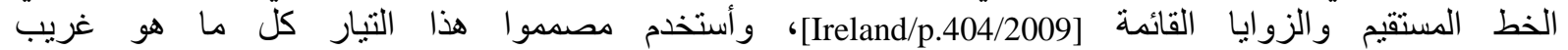

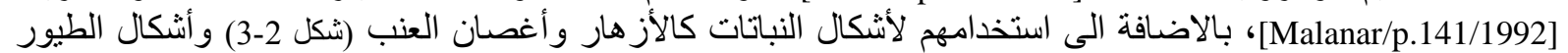

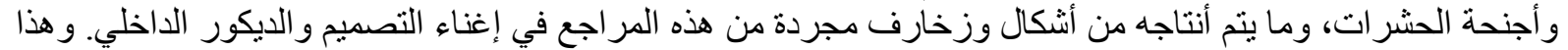

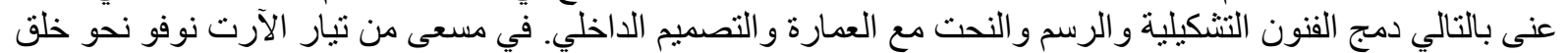

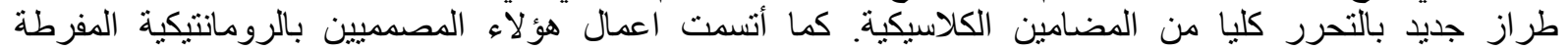

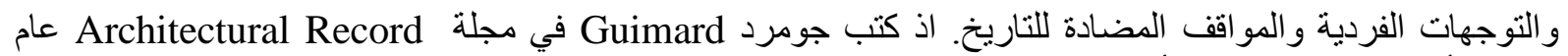

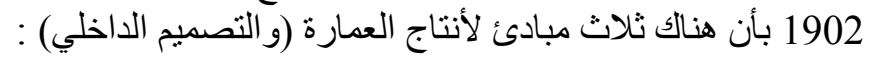

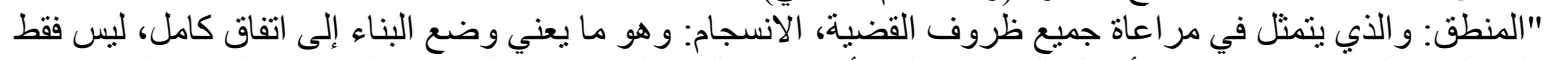

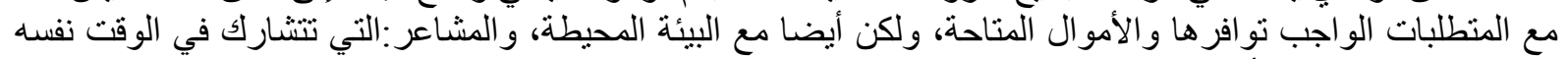

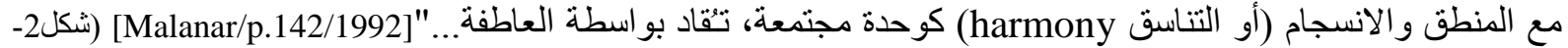

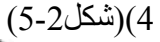
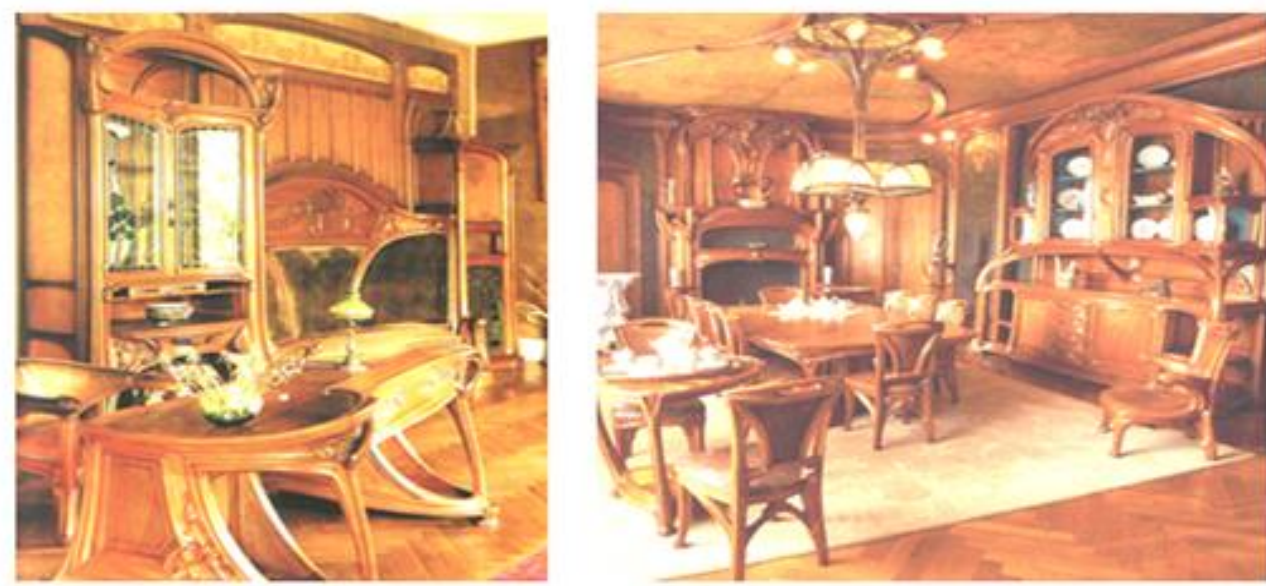

Eugene vallin- Masson House, Paris1903 (5-2)(4-2)

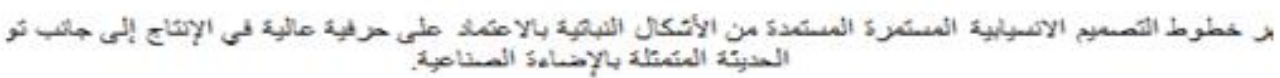

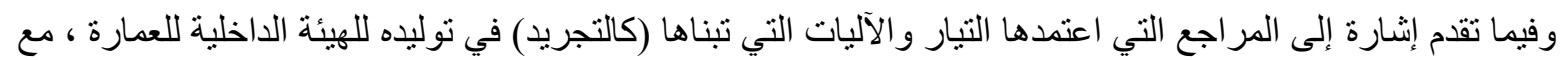

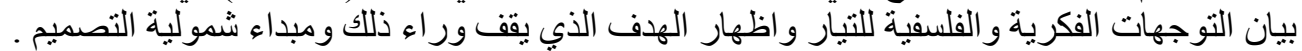

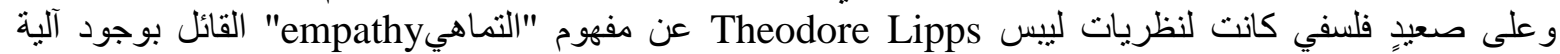

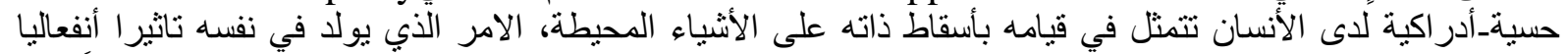

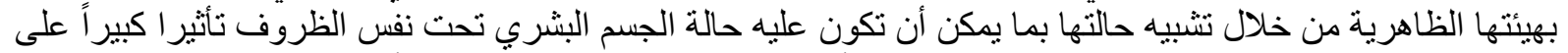

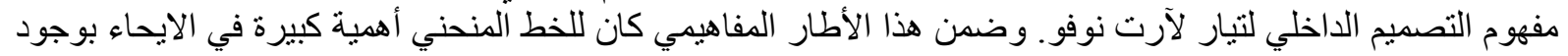




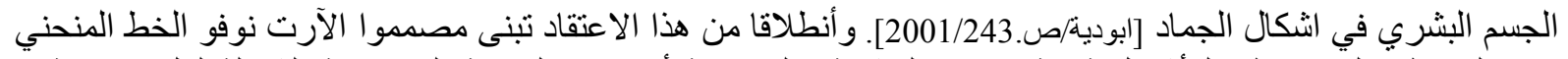

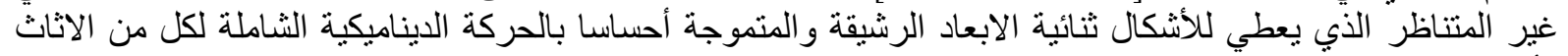

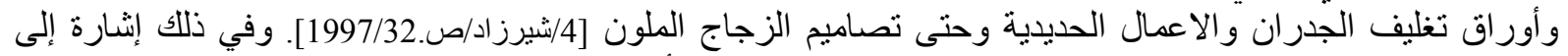

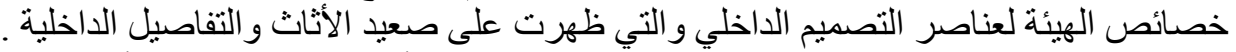

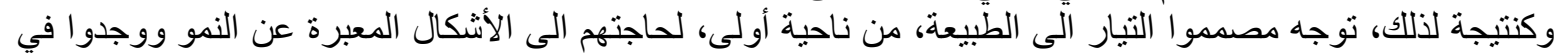

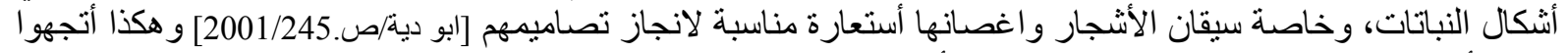

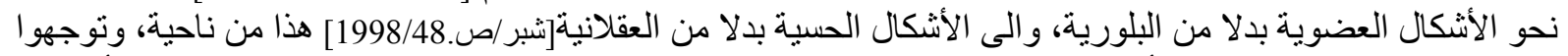

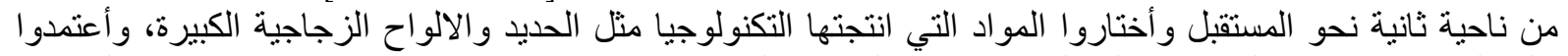

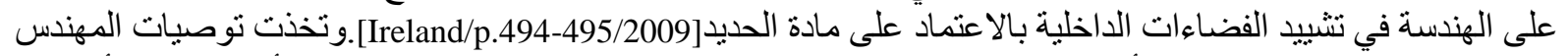

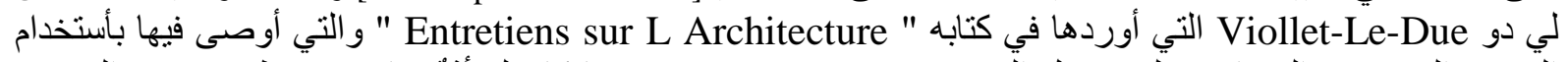

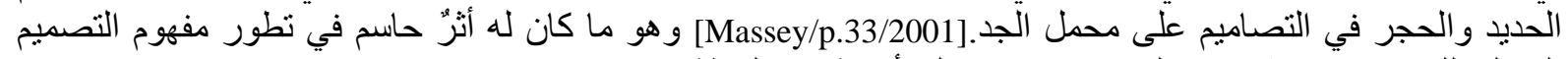

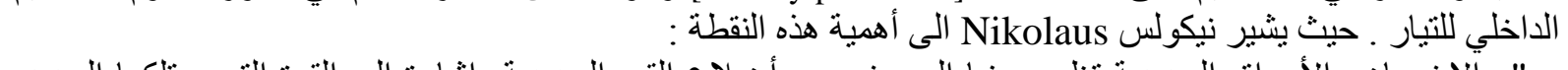

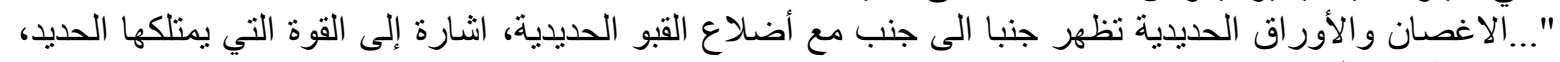

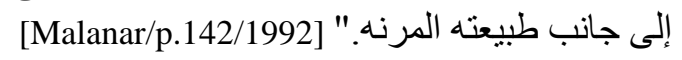

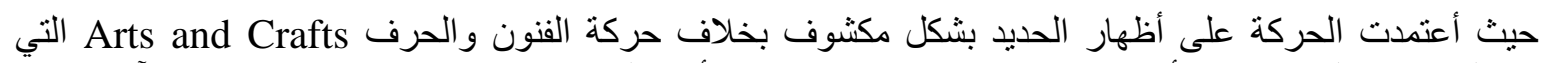

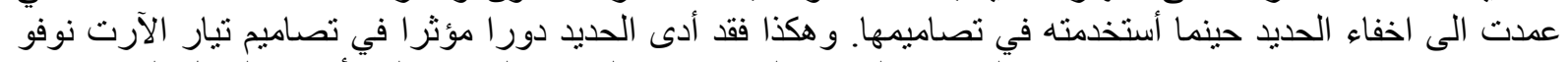

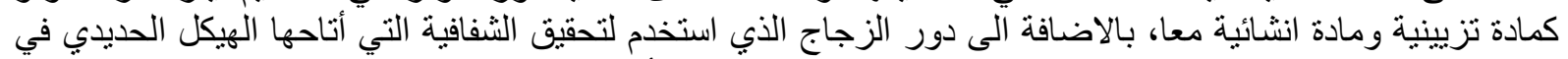

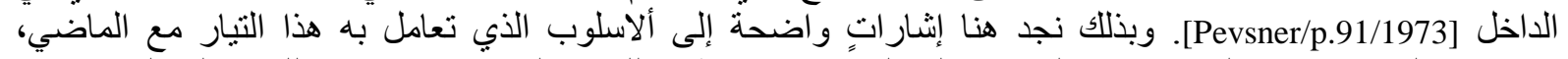

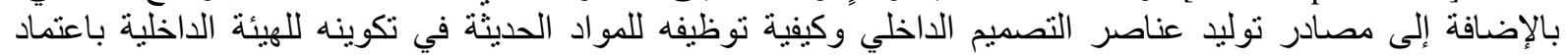
الهندسة وسيلة لذلك. ظهرت هذه الأثار في تصاميم داخلية لمصممين امثال فيكتور هورتا Victor Horta ( الذي كان كان أول مصمم يقوم

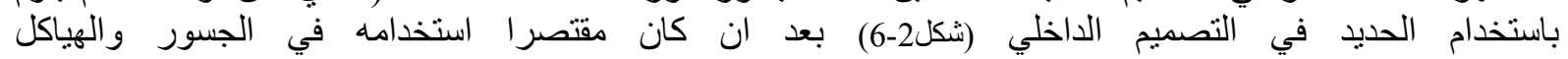

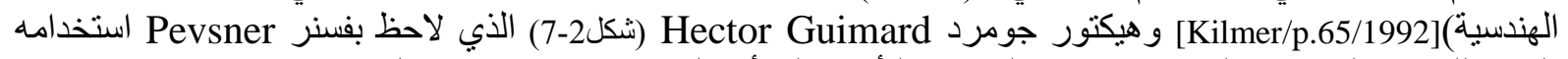

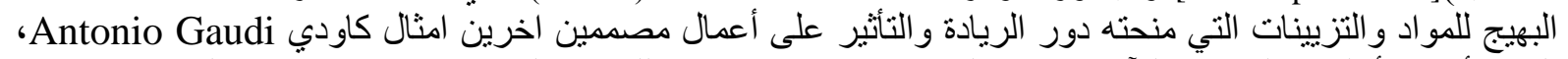

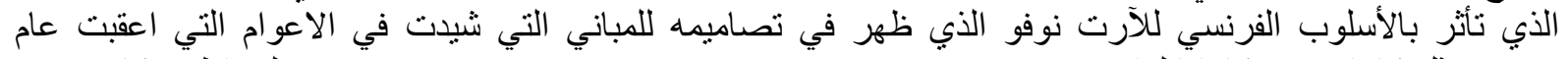

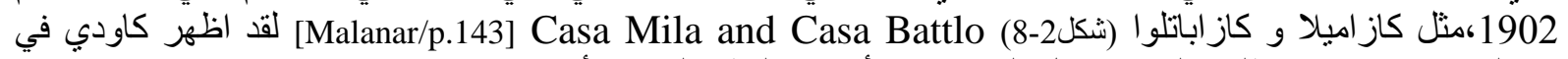

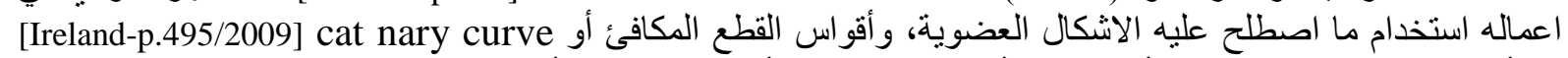

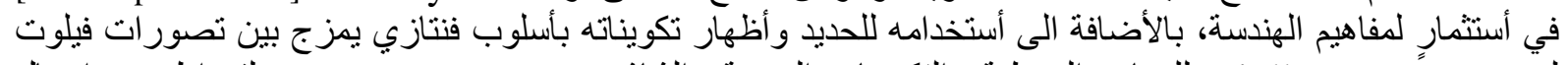

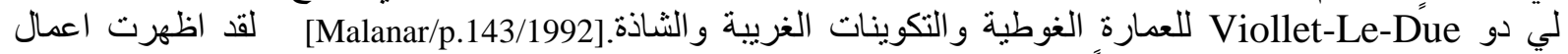

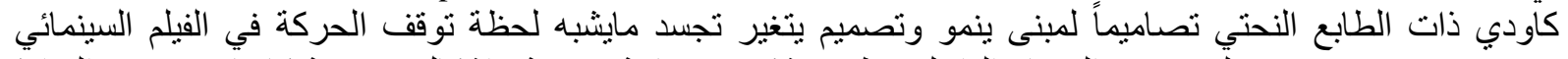
constant motion

بفعل الرياح [Kilmer/p.66/1992].

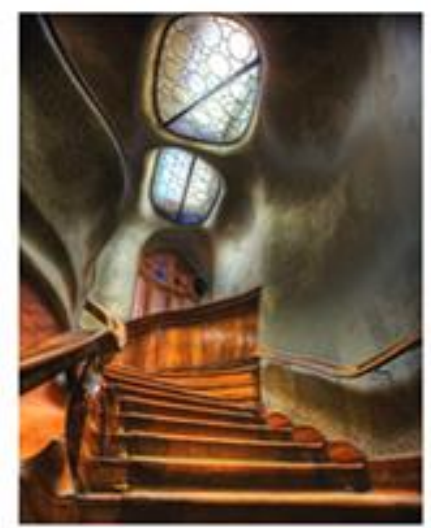

Antoni Gaudi,Casa (\$-2) Batlló,1904

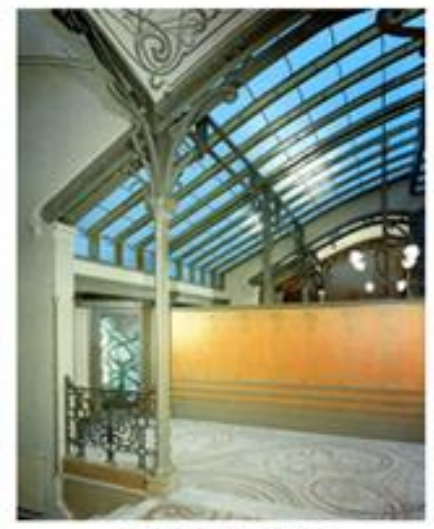

Hector $(7-2)$ is: Guimard,Castel Beranger,Paris, 1894-9

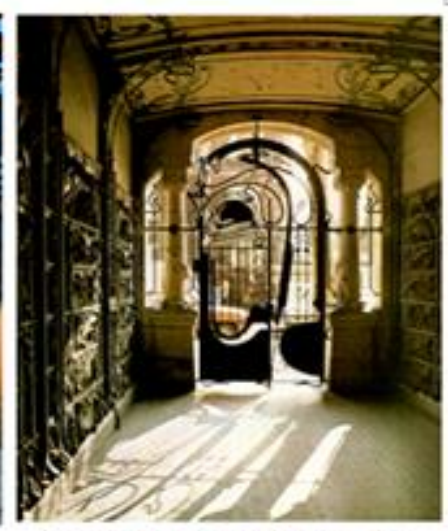

Victor Horta,Hotel (6-2) تك Solvay, 1900

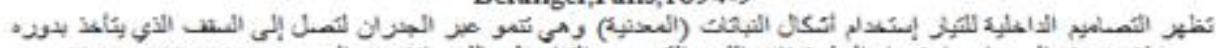

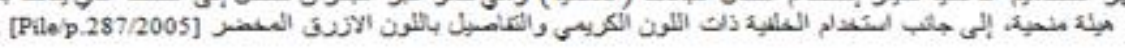




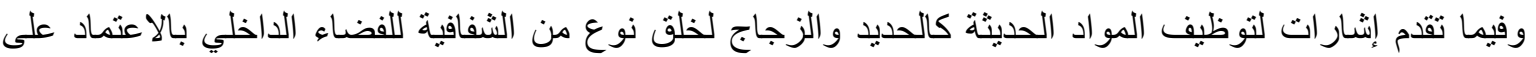

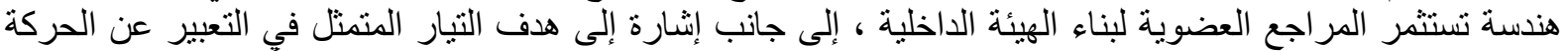

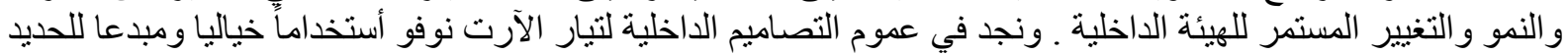

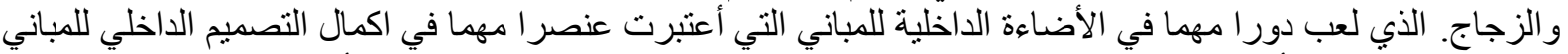

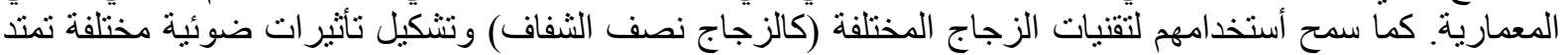

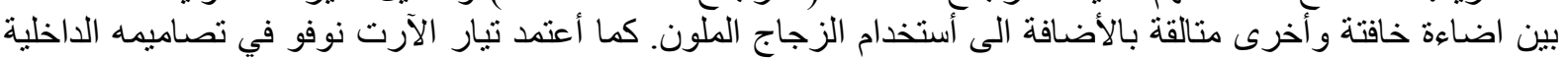

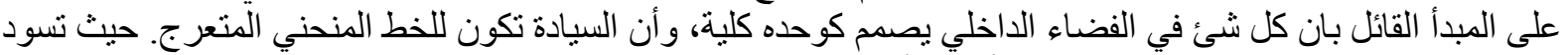

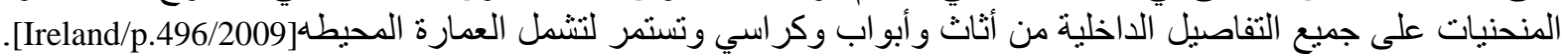

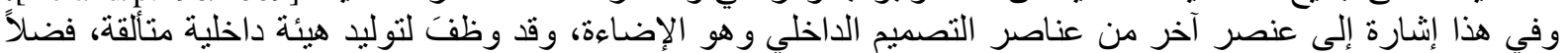

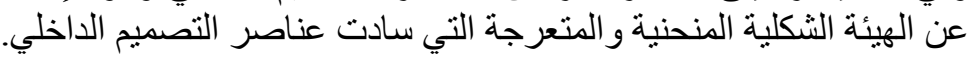

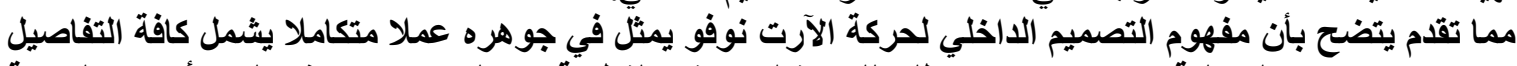
والمون "unified whole"

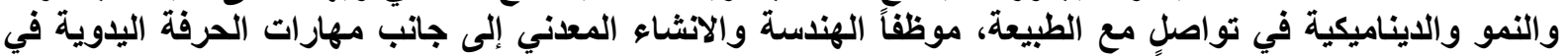

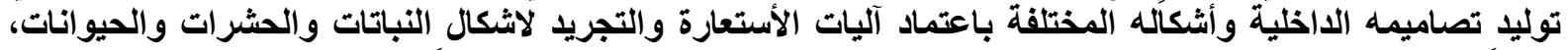

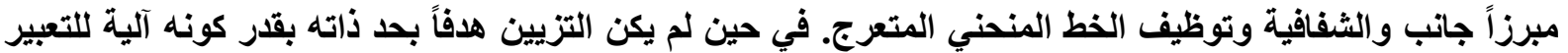
الرمزي والإرتباط بالطبيعة من جهة والسعي نحو التعبير عن النمو والتغيير المستمر من جهة أخرى.

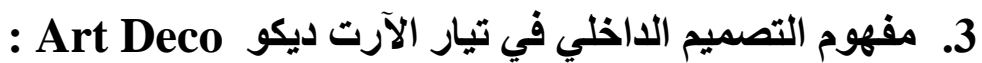

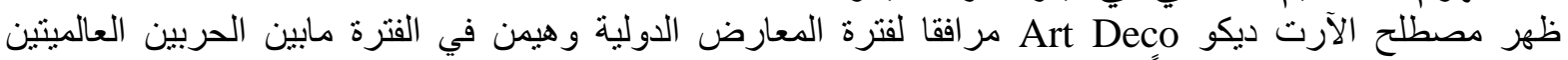

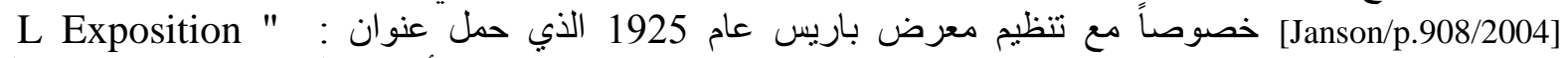
"International des Arts Decoratifs el Industriels Modernes

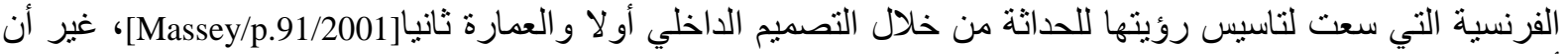
أستخدام هذا المصطلح لم يظهر إلا في عام 1968 مع ظهور كتاب(Art Deco of the 20s and 30s) لمؤلفه الإنه هلير Bevis Hillier عكس هذا الأسلوب كفاح المصممين الأوربيين بعد الحرب العالمية لأيجاد توجه تصميمي يعكس ، القرن العشرين، ويجد له خطا بعيدا عن أسلوب الآرت نوفو Art Noveau وتيار الحداثة Modern Movement

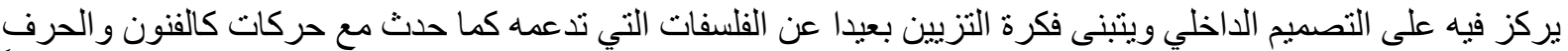

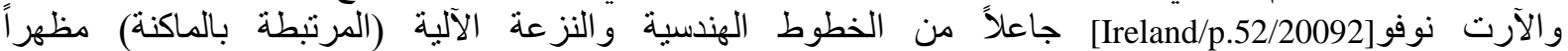

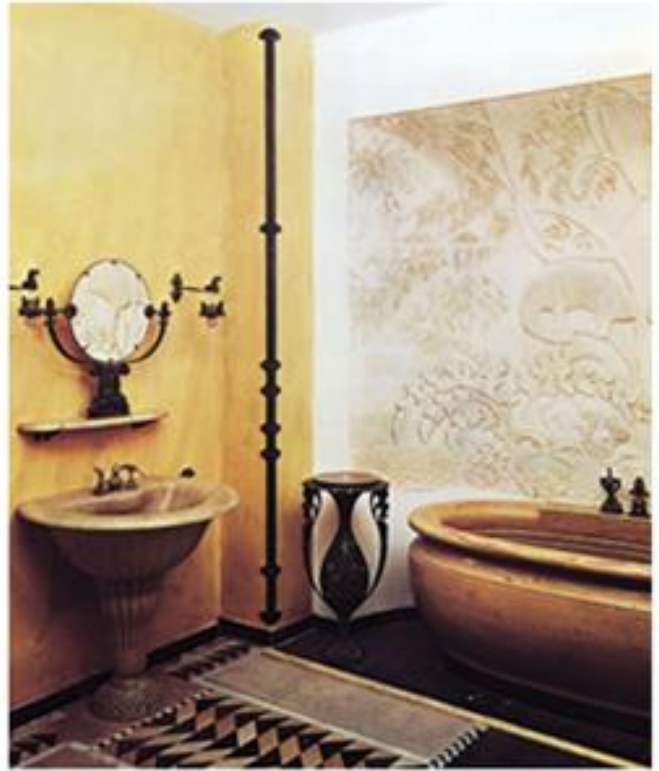

Amand-Albert, bathromm,1920(1-3) US:

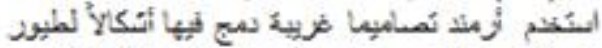

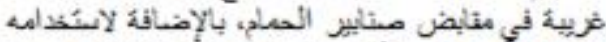

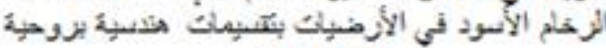
Art Deco- (الأن له [Kilmer/p.74/1992]. مما أشر مبدأين للتيار تمثلا بفكرة التزيين و وهندسية الاشكال و العناصر.

فهو على خلاف الحركات التصميمية الحداثوية الأخرى (الحداثة و الاسلوب العالمي) لايعتمد بشكل رئيسي على الألئي الهتمام

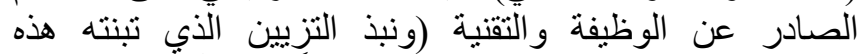

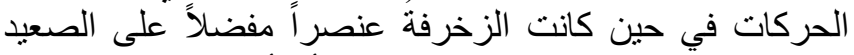

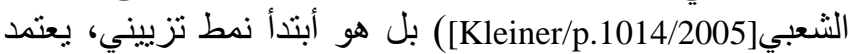
على أخذ مكانته في سلسلة الانماط او الاساليب التاريخية القديمة حيث المصمم أو الزبون يمكنه الأختبار من مراجع مختلفة الألفة الألية

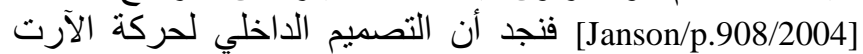

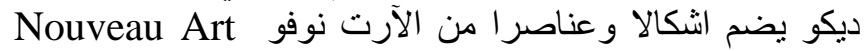
والفن التكعيبي Cubism وحضارة الازتلك الأكن

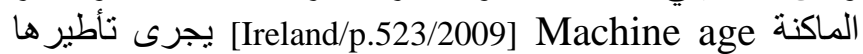

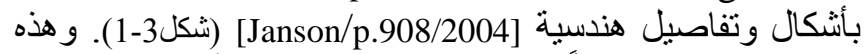
بمجمها شكلت مر اجعاً لهذا التيار جرى توظيفها بأساليب هندسية.

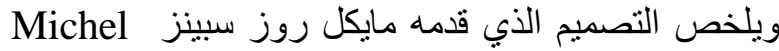
لنموذج تصميم غرفة في معرض باريس لفن مان الديكور Salondes Artistes Decorateurs عام 1928 هذا التوجه. حيث يظهر السجاد ذو النمط القريب من الفن التكعيبي، 
ويظهر على الحاجز القابل للطي رسومات مرتبطة بالفن الافريقي التقليدي، بينما تُظهر المرآة الكبيرة وتراكيب الإضـاءة

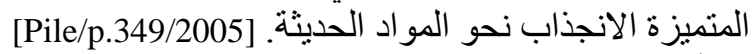

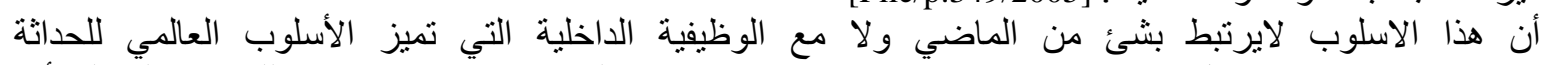
"International Style"

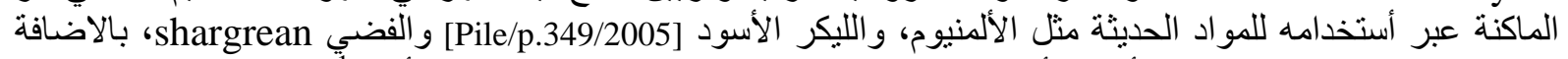

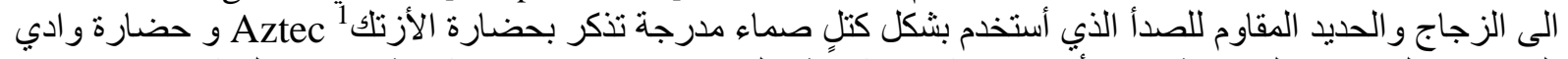

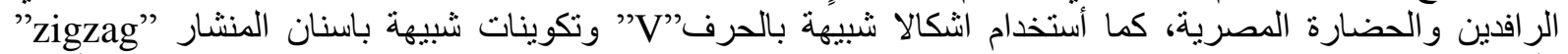

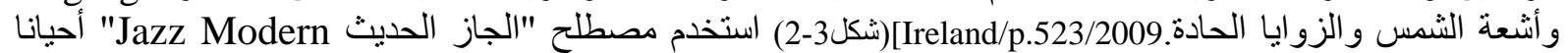

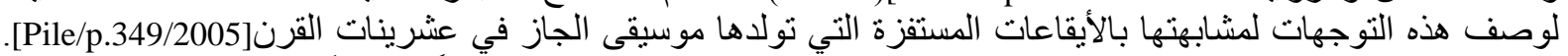

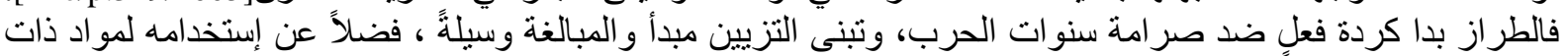

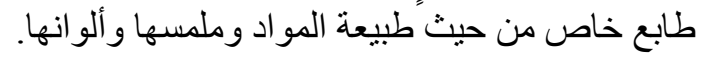

لقد أحب مصمموا الآرت ديكو الداخليين كل ما هو غريب، وأستخدموا الواناً فاحمة واظهرو التها تكرارا لأشكال هندسية

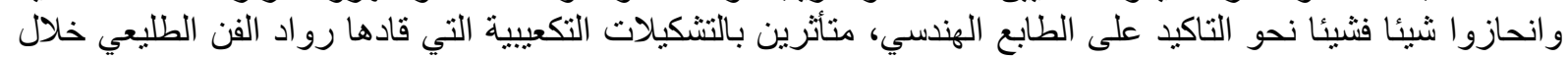

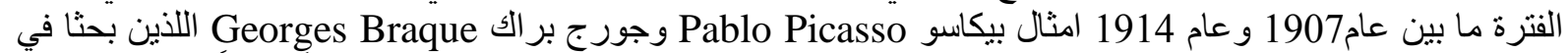

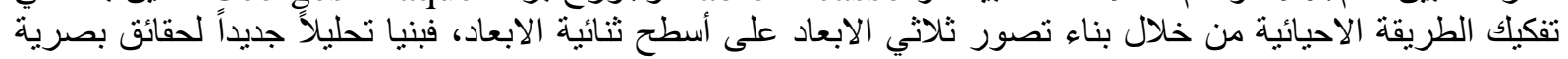

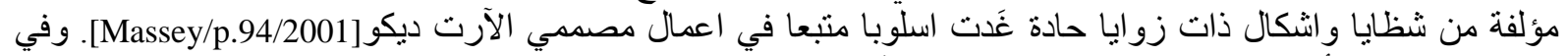

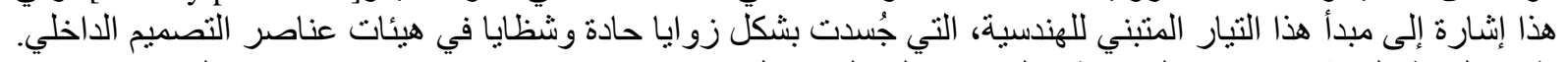

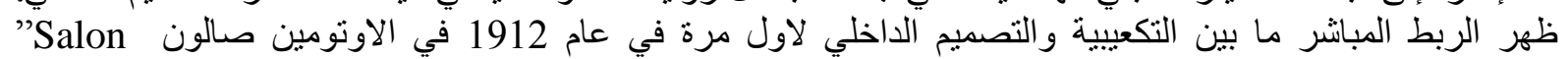

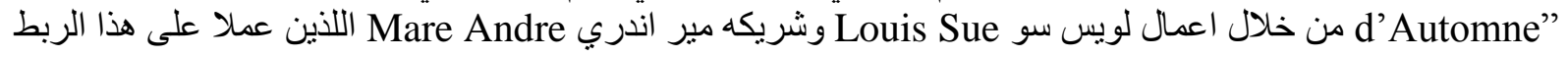

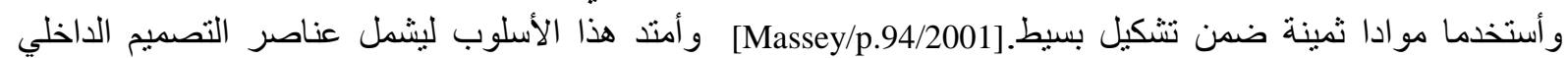

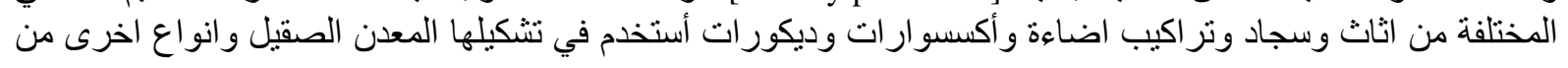
المو اد العاكسة [Ireland/p.524/2009] وجلود الحيو انات [Massey/p.92/2001)

وفي مواكبة من الآرت ديكو للأوق والموضة السائدة سعى مصمموا التيار من امثال باول بويرت Paul Poiret

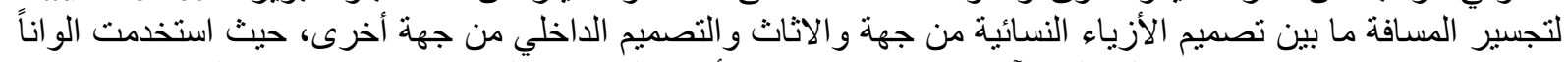

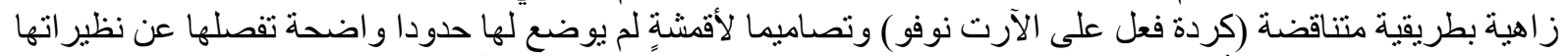

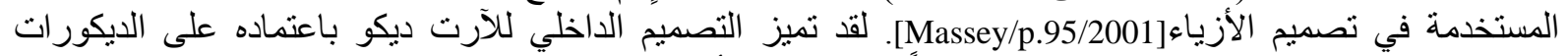

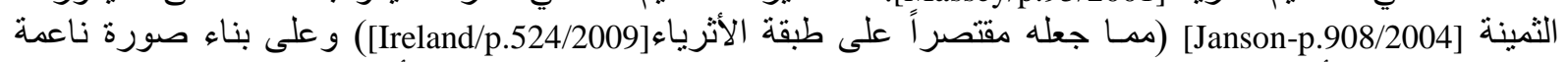

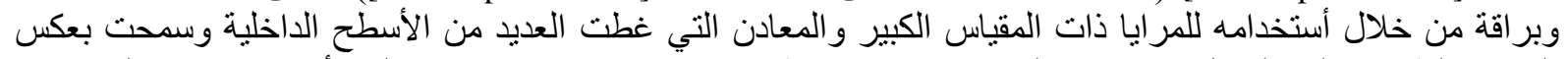

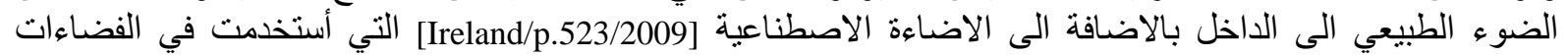

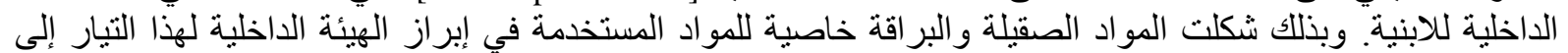

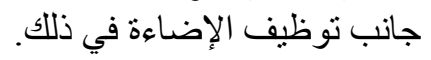

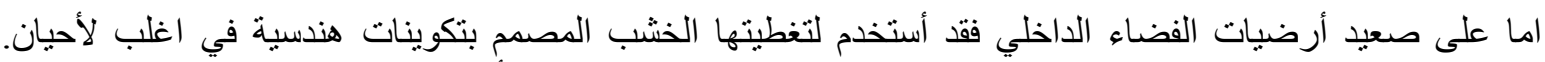

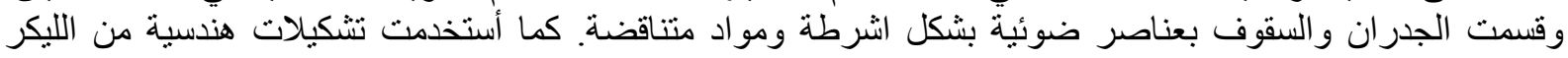

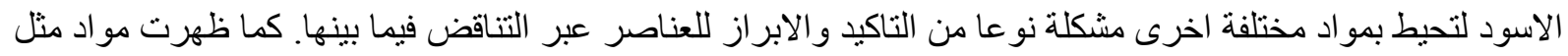

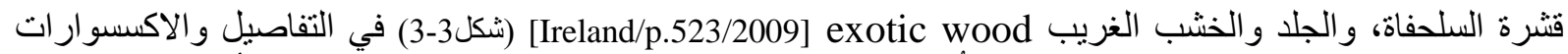

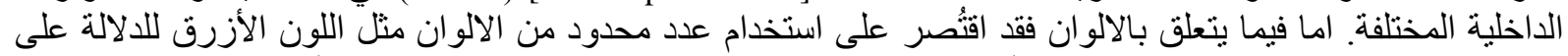

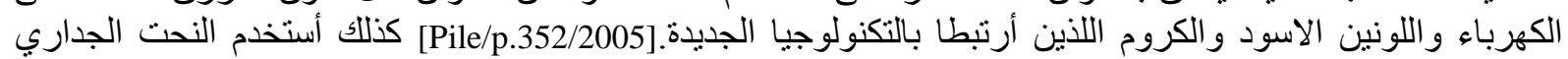

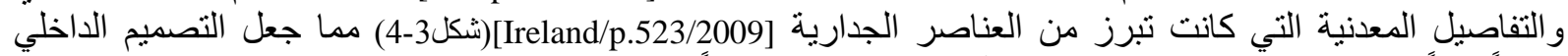

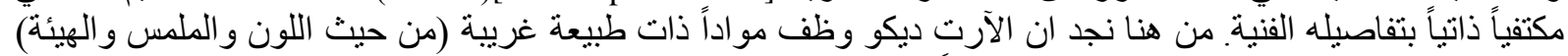
و غالية الثمن حملت معها بريقها لثنة الخاص، ومعتمداً التناقض وسيلة وطن للربط بينها.

1 حكمت إمبر اطورية الآزتك منذ سنة 1428م، وحتي 1521م و هذه الإمبر اطورية كانت أساس حضارة الأزتك. وكانت الإمبر اطورية تحكم من و ادي المكسيك

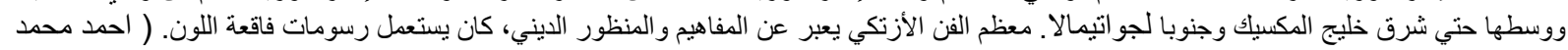




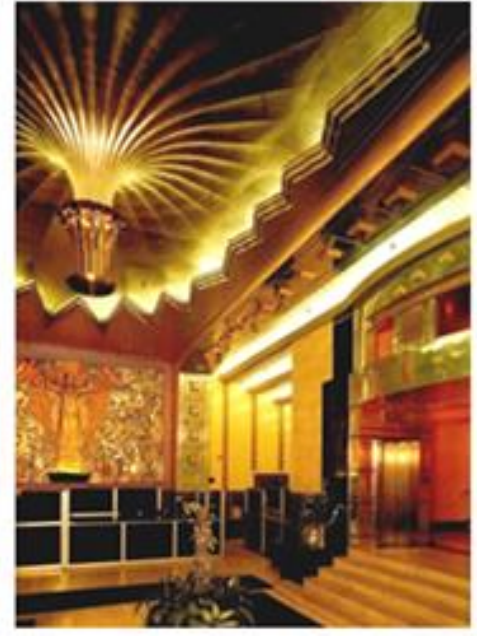

Ellis\&Clarke,Daily (4-3) Express, 1931

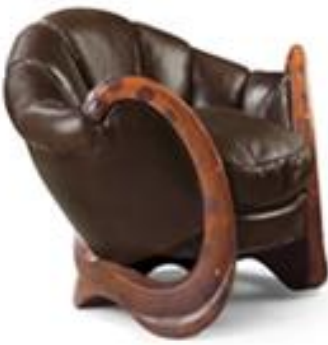

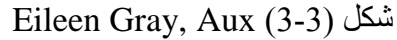

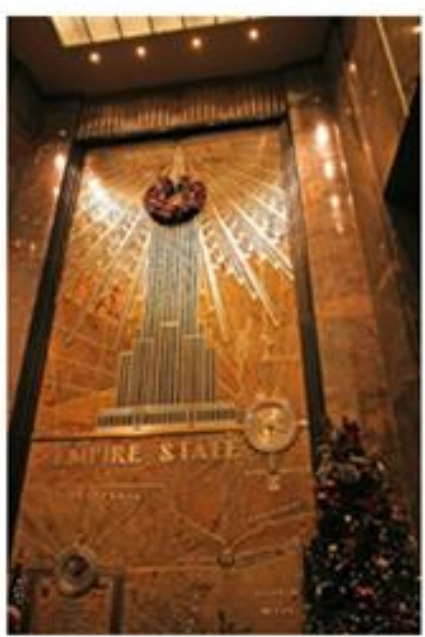

William Van Alen, (2-3) Chrysler Building 1883-1954

\footnotetext{
Dragons, 1917

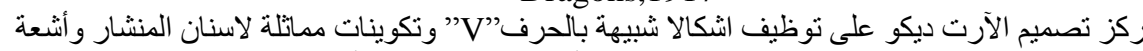

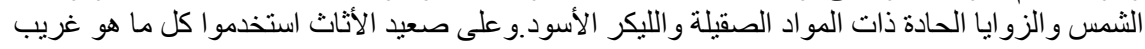

.[Pile/p.349/2005] [Ireland/p.523/2009]
}

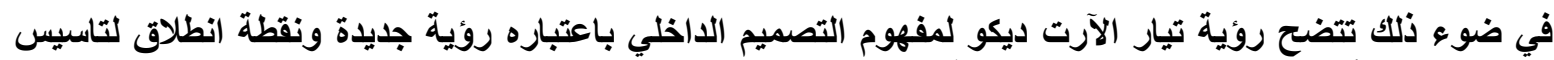

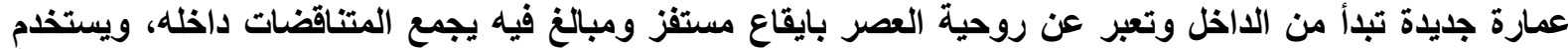

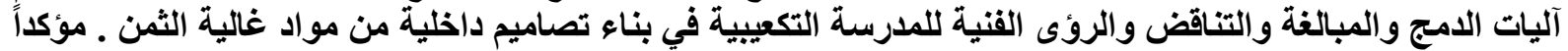
على الهندسية والتزيين بنمط خاص والمرتبط بمر اجع مختلفة.

\section{Modernism مفهوم التصميم الداخلي لحركة الحداثة}

يشير كرتز Curtis في كتابه "Modern Architecture since 1900" الى ان الفترة التي اعقبت عام 1920

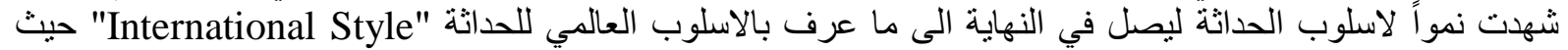

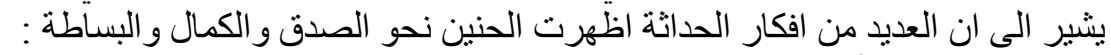

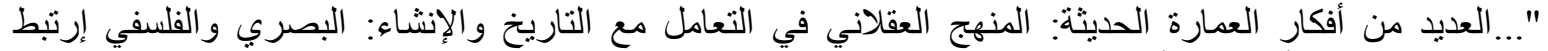

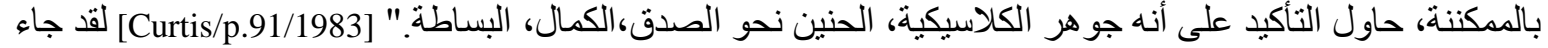

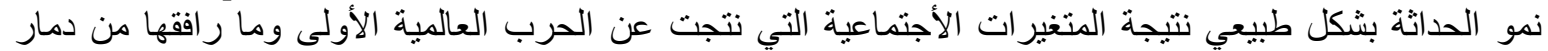

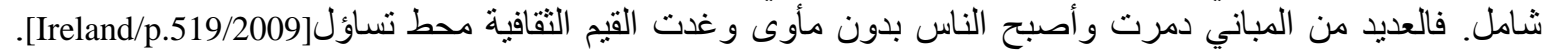

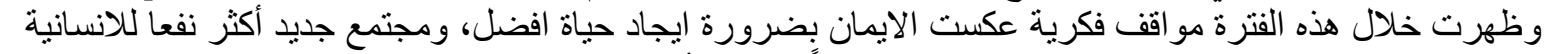

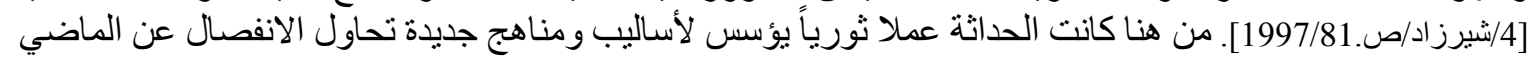

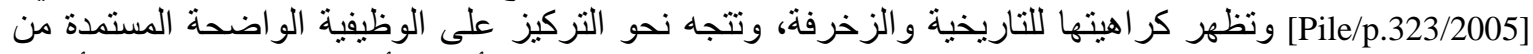

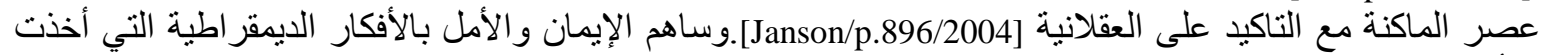

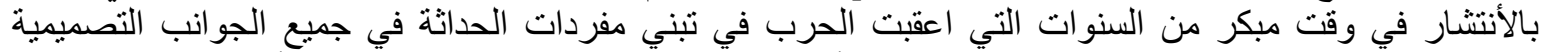

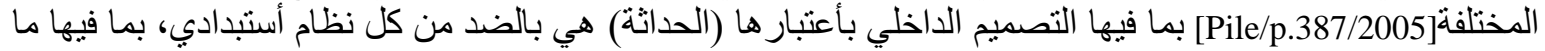

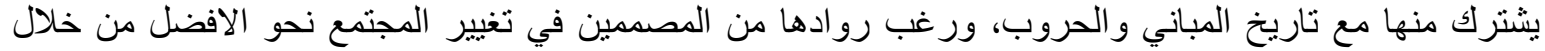

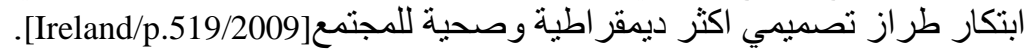

كما قادت العديد من التقنيات المطورة و التكنولوجيا الى تغيير طبيعة الفضاء الداخلي بالأضافة الى أثر ها على الجانب

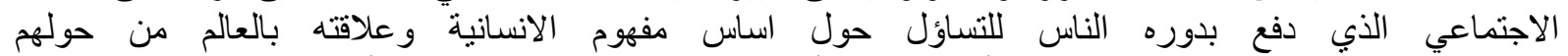

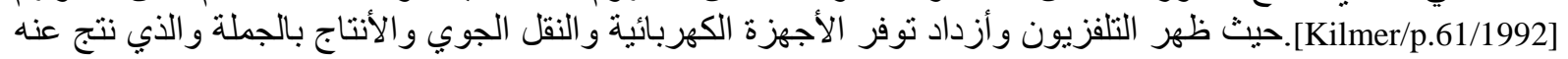




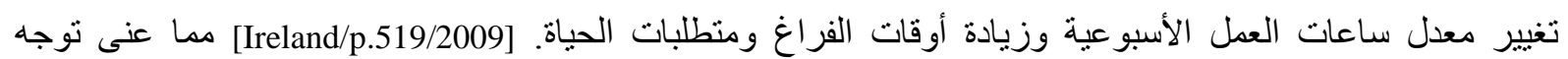

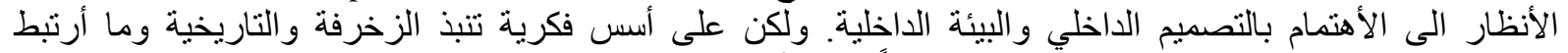
بالماضي مع تبني الوظيفية التي شكلت بمجملها جو انباً فكرية أرتكز عليها لئها تيار الحداثة في تصميمه الداخلي.

أن التطور المهم الذي حدث على صعيد التصميم الداخلي مع بدايات القرن العشرين كان بدافع من المصممين الذين سعوا

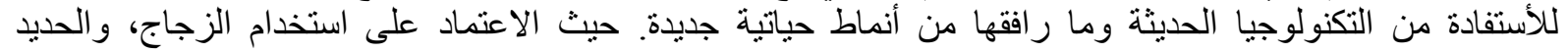

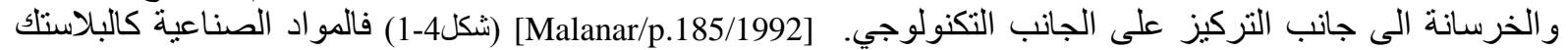
حلت محل المواد السابقة، وأستخدمت المنسوجات البرات الصناعية لعمل السجاد والأقششة المختلفة على نطاق واسع. وأستعين

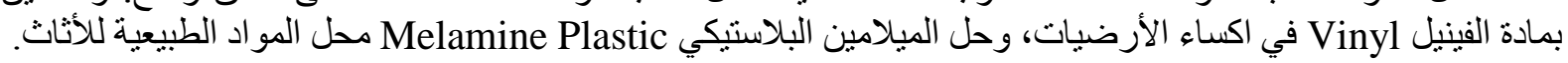

[Pile/p.387/2005

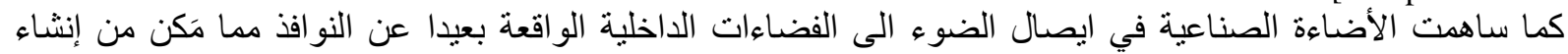

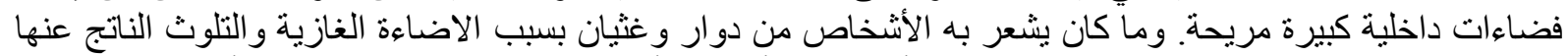

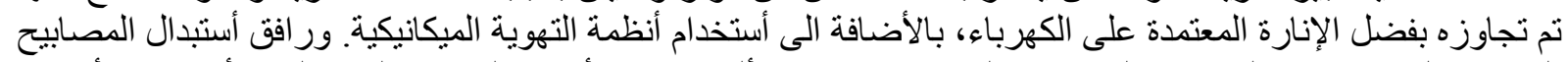

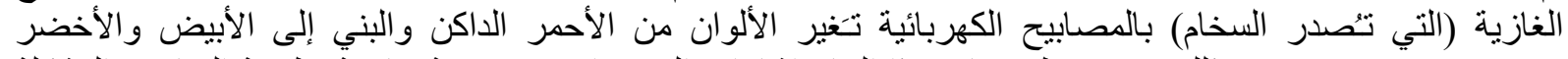

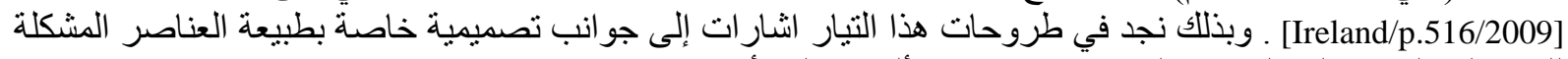

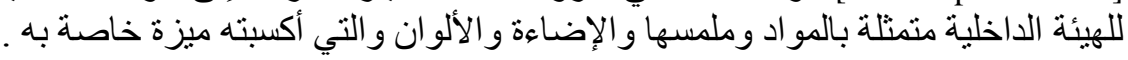

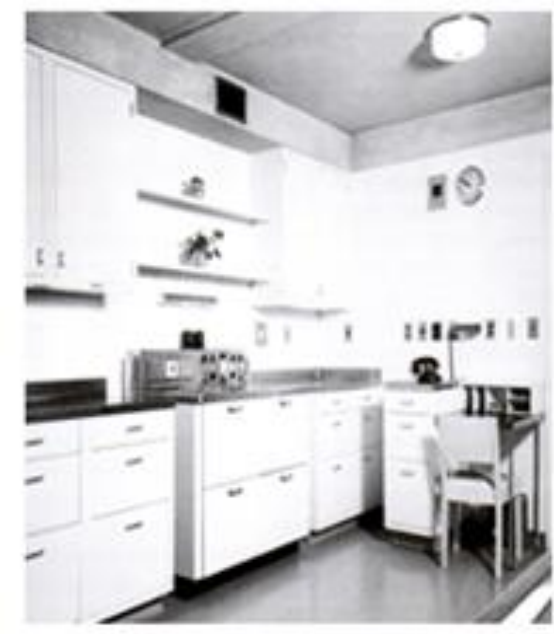

Kraetsch \& Kraetch, Butler (2-4)شكل House, 1936

البساطة والمظهر الوظيفي واستخدام مواد سهلة

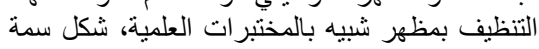
لمطابخ تيار الحداثة.

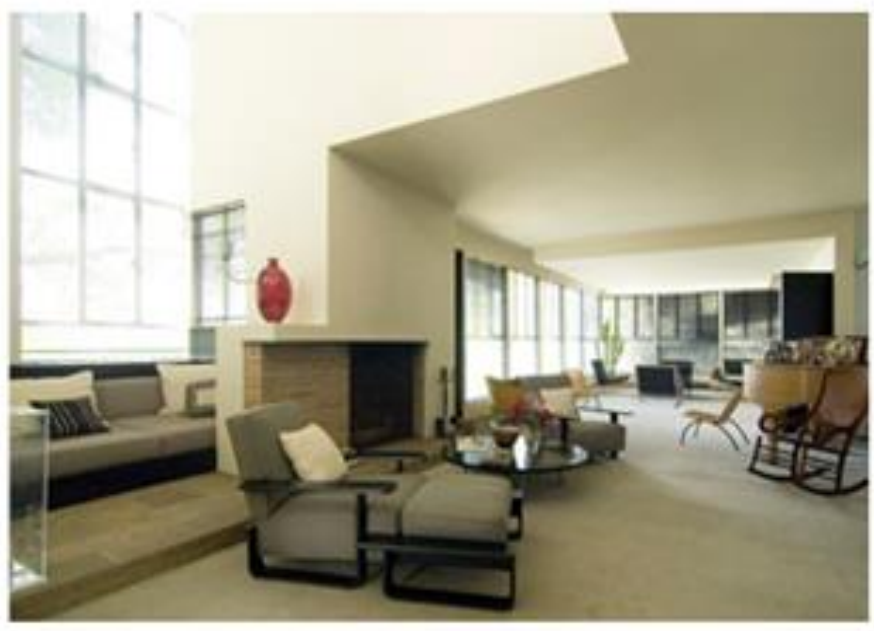

The Kaufmann Desert House - 1946 (1-4)

الفضاء المفتوح المرن إلى جانب توظيف المواد الحديثة ذات الالوان

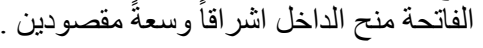

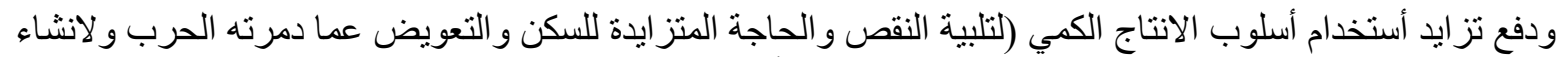

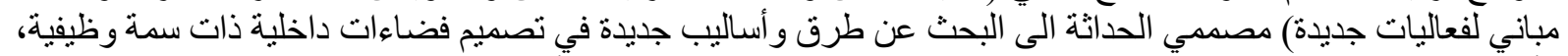

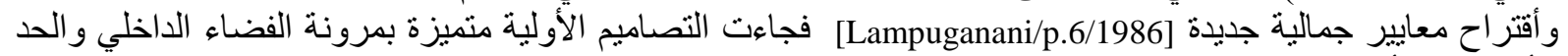
الأدنى من الأشياء الضرورية الضئة النفعيـة

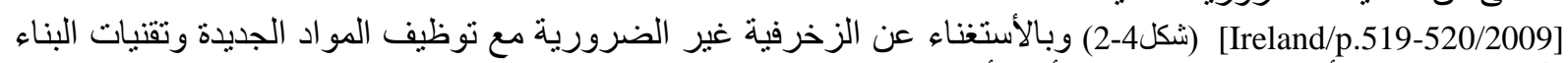

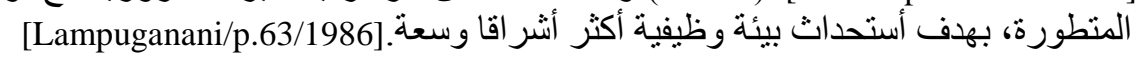

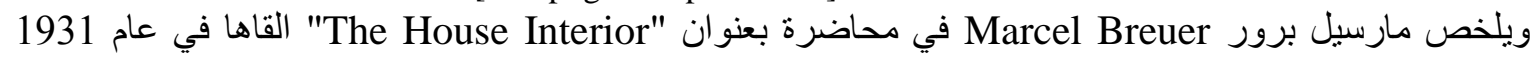

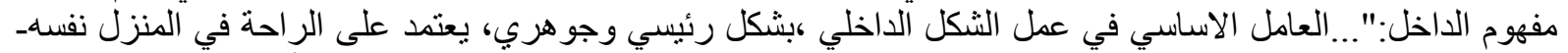

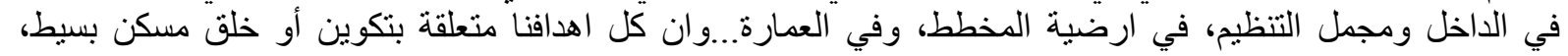

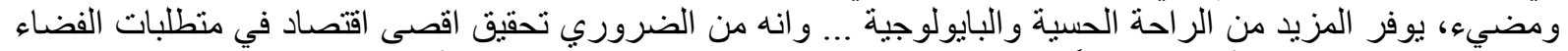

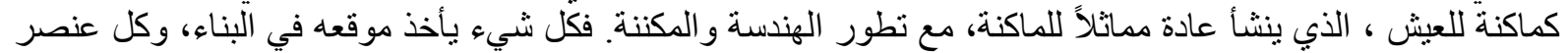


يأخذ موقع محدد خاص باه... وكل شيء مقيس باقل ابعاد ممكنة وبشكل يتعاثق مع بقية الاجز اء( كما تتعانق نروس

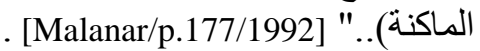

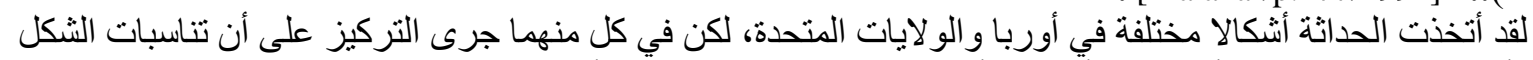

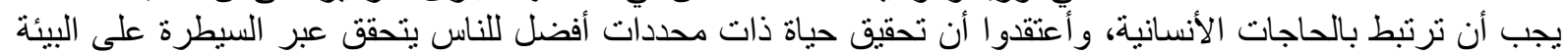

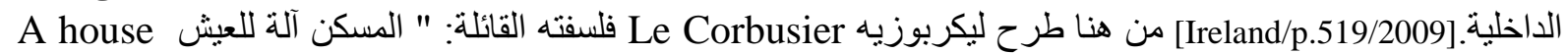
Jis a machine for living in

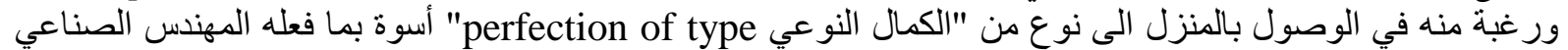

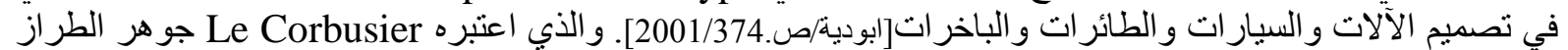

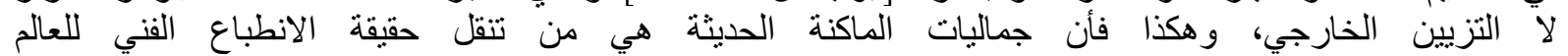

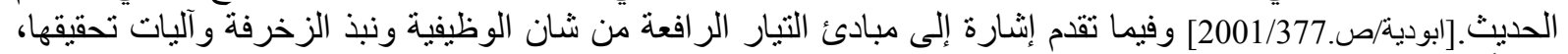

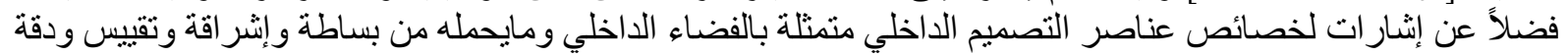
ووضوحية.

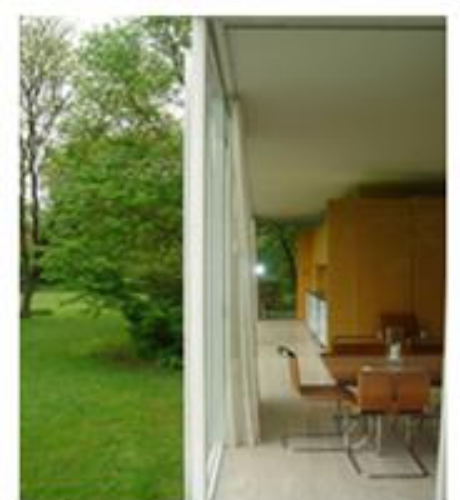

Mies Van der Rohe (4-4) شكل farnsworth house, Illinois,946-50

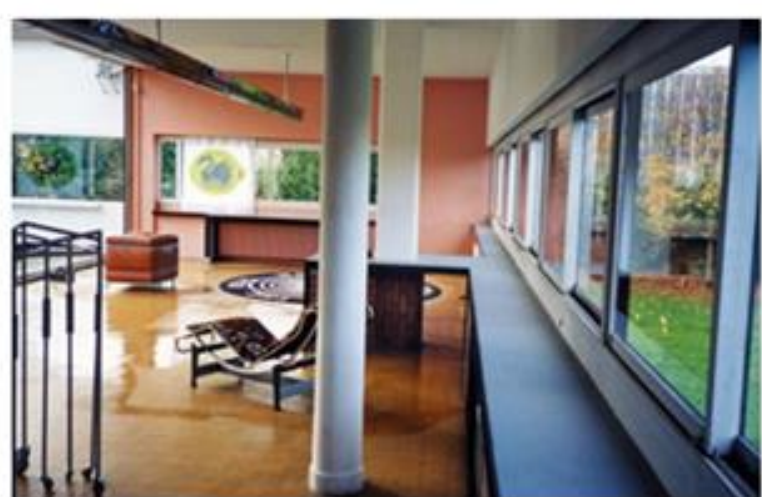

Le Corbusier, Villa Savoye,Poissy,1929 (3-4)

الفضاء الانسيابي الممتد نحو الخارج والخالي من العناصر التاريخية والزخرفية كان سمة بارزة لتيار الحداثة إلى جانب توظيف الحد الادنى من العناصر في تشكيل الهيئة الداخلية للعمارة.

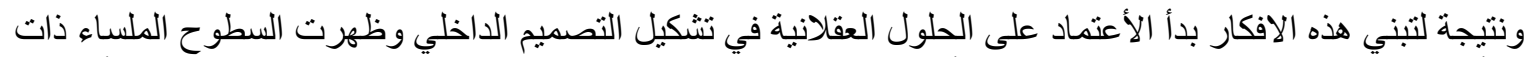

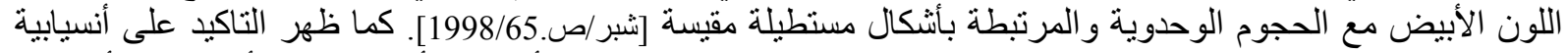

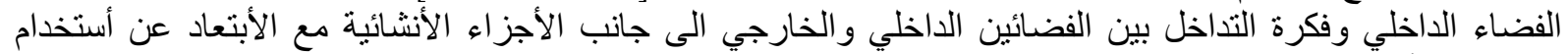

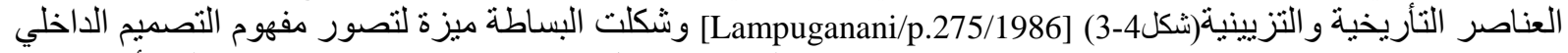

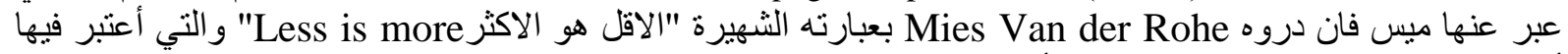

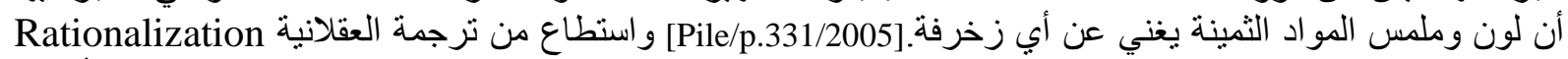
و التقييس Standardization اللى معاني فعالة [Janson/p.903-904/2004] معتمدا مفاهيم التجريدية النقية والأشكال

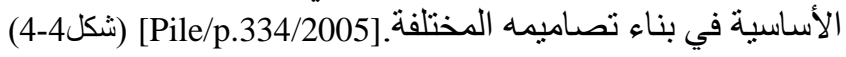

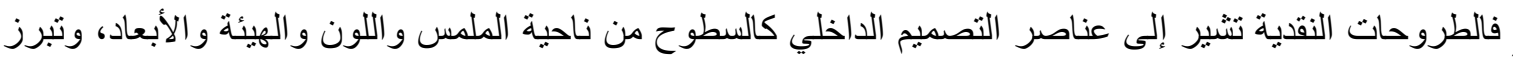

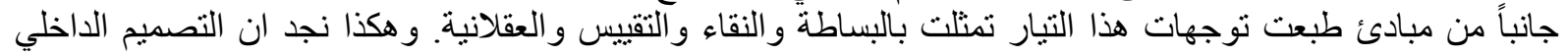

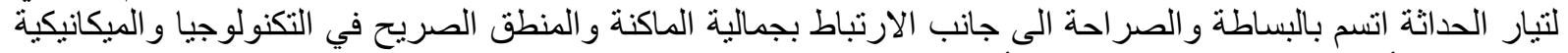

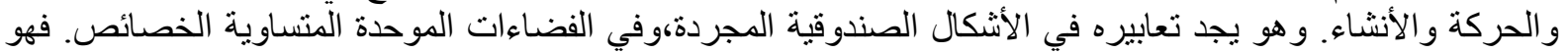

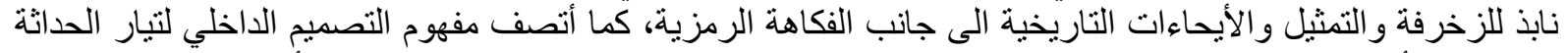

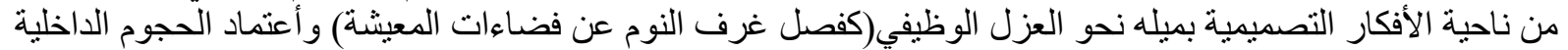

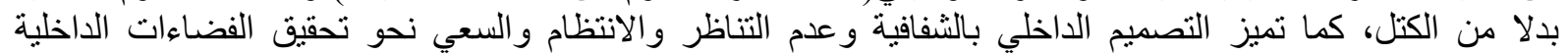

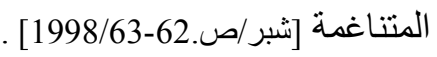


وعلى هذا الأساس يتضح أن هدف التصميم الداخلي لتيار الحداثة هو توفير بيئة انسانية مريحة ومسيطر عليها

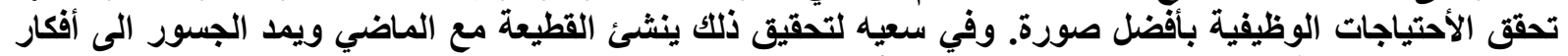

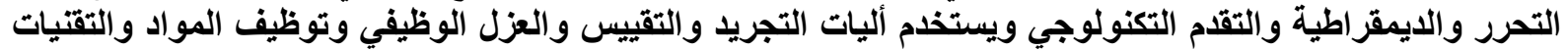

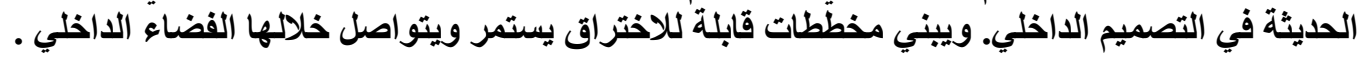

\section{Post-Modernism مفهوم التصميم الداخلي لتيار مابعد الحداثة :}

في وقت مبكر من سبعينيات القرن العشرين رفض العديد من قادة الحداثة تثويه سمعتها على صعيد التصني التصميم الداخلي

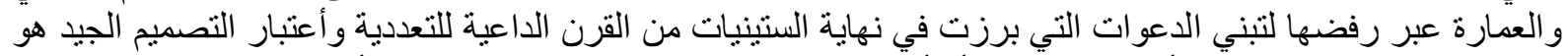

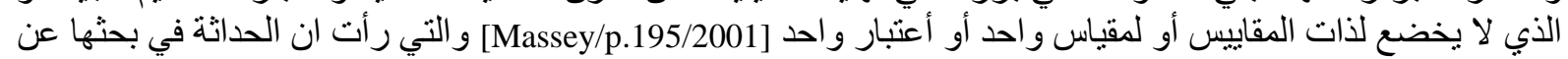

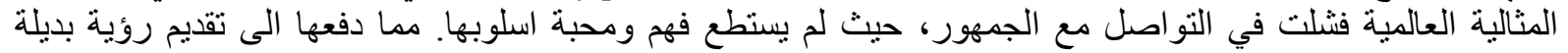

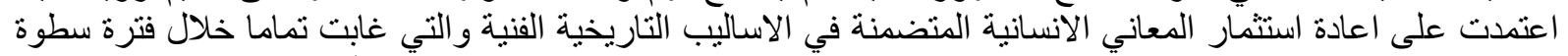

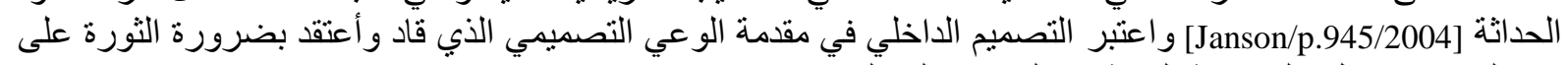

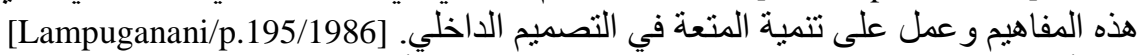

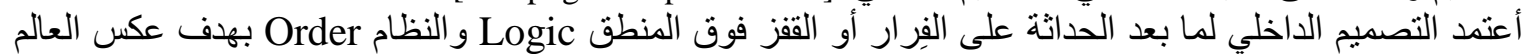

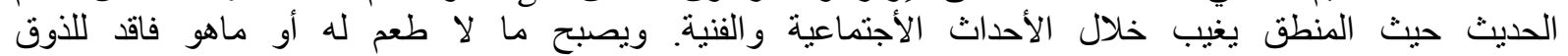
tastelessness،Eccentricity

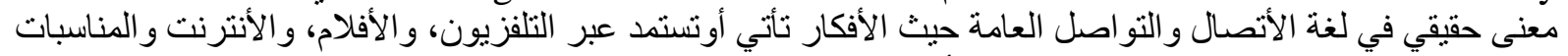

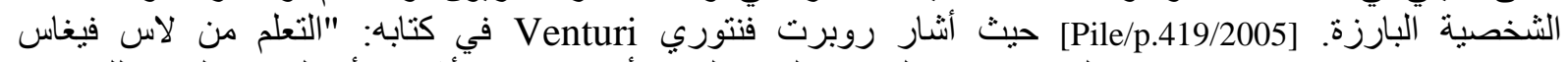
Learning From Las Vegas

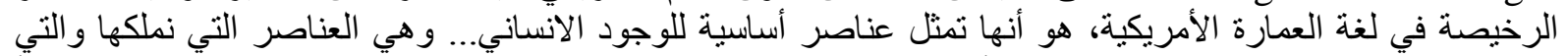

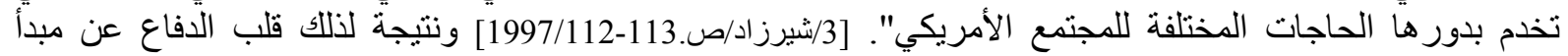

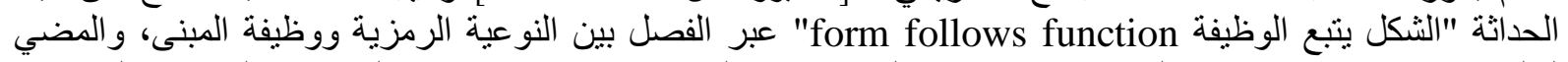

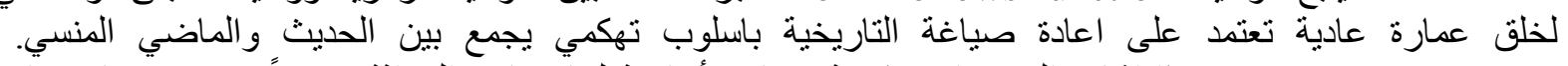

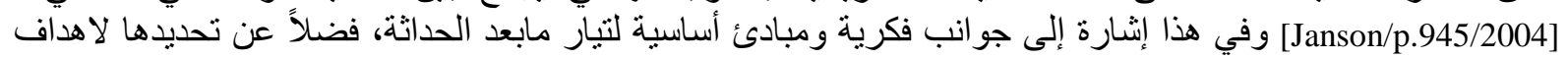

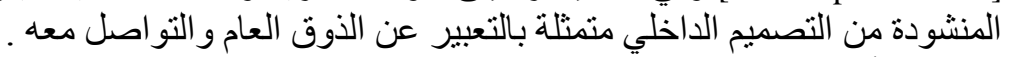

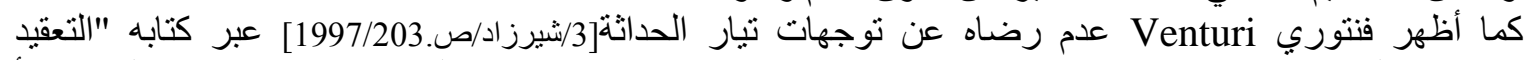

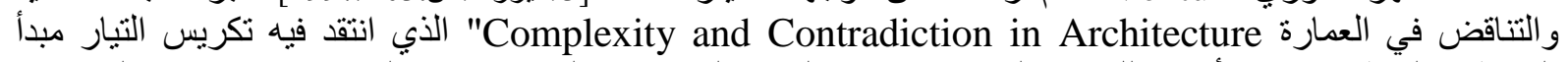

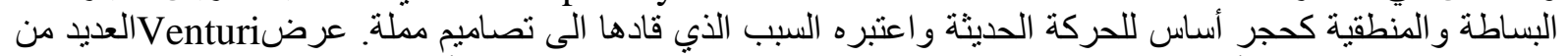

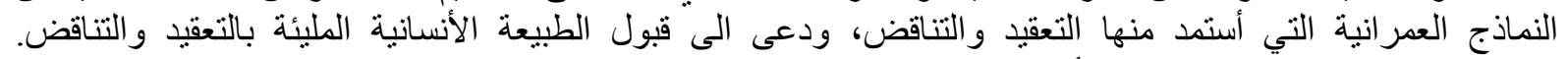

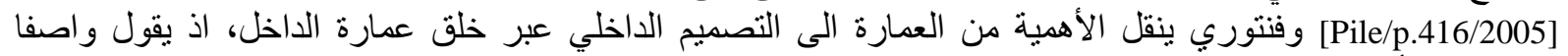

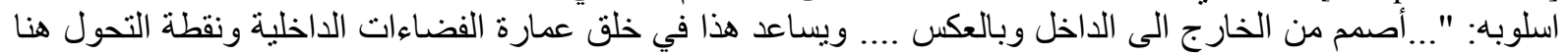

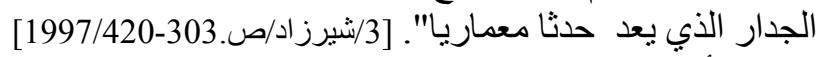

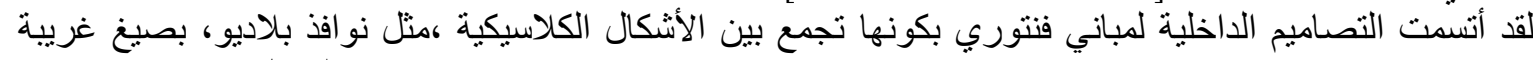

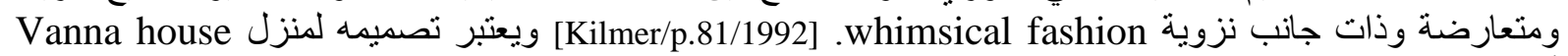

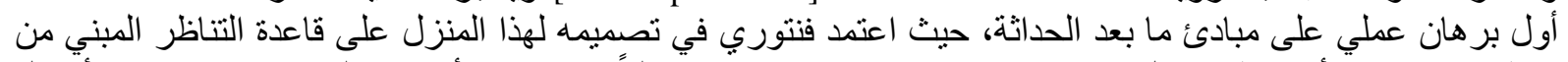

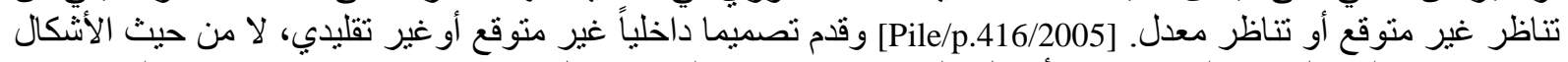

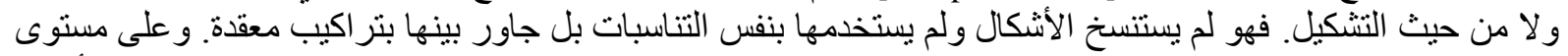

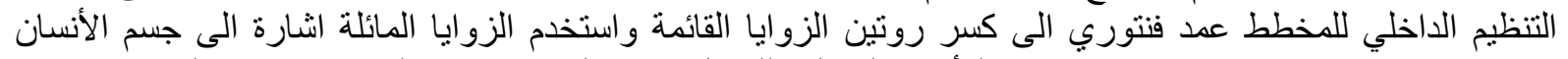

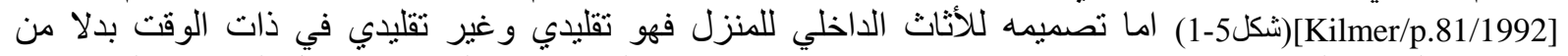

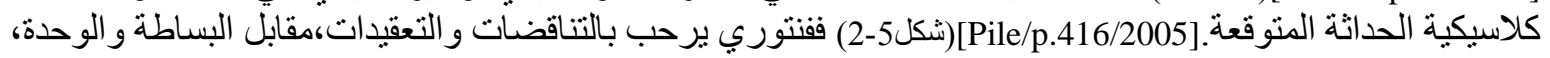

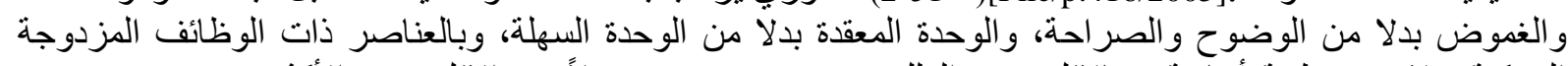

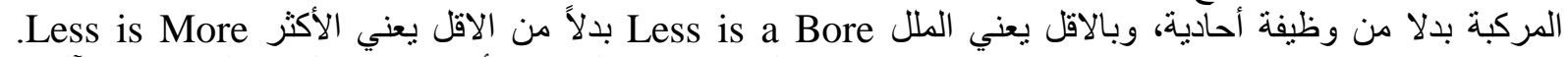

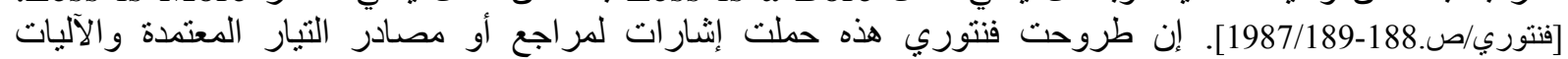

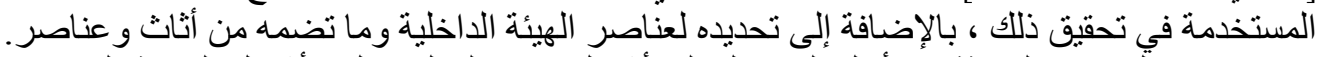

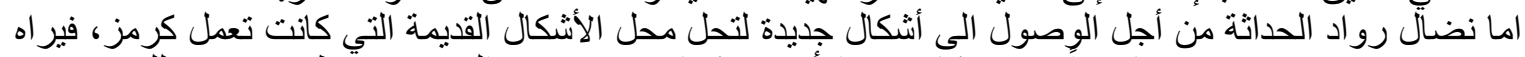

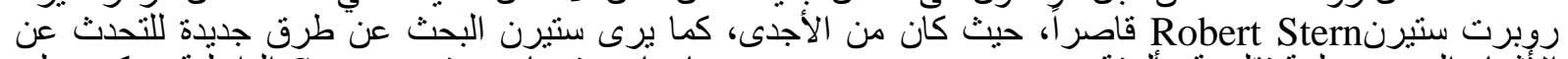

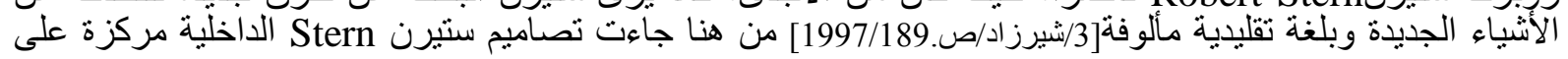


التفاصيل الصغيرة التي تعيدنا الى الكلاسيكية من جهة وتحملنا الى الامام نحو تتوع ما بعد الحداثة من جهة أخرى

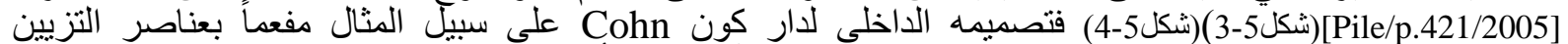

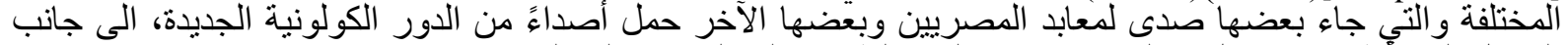

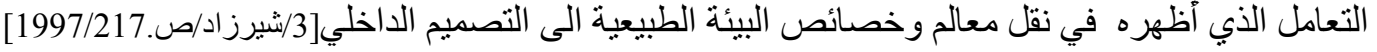
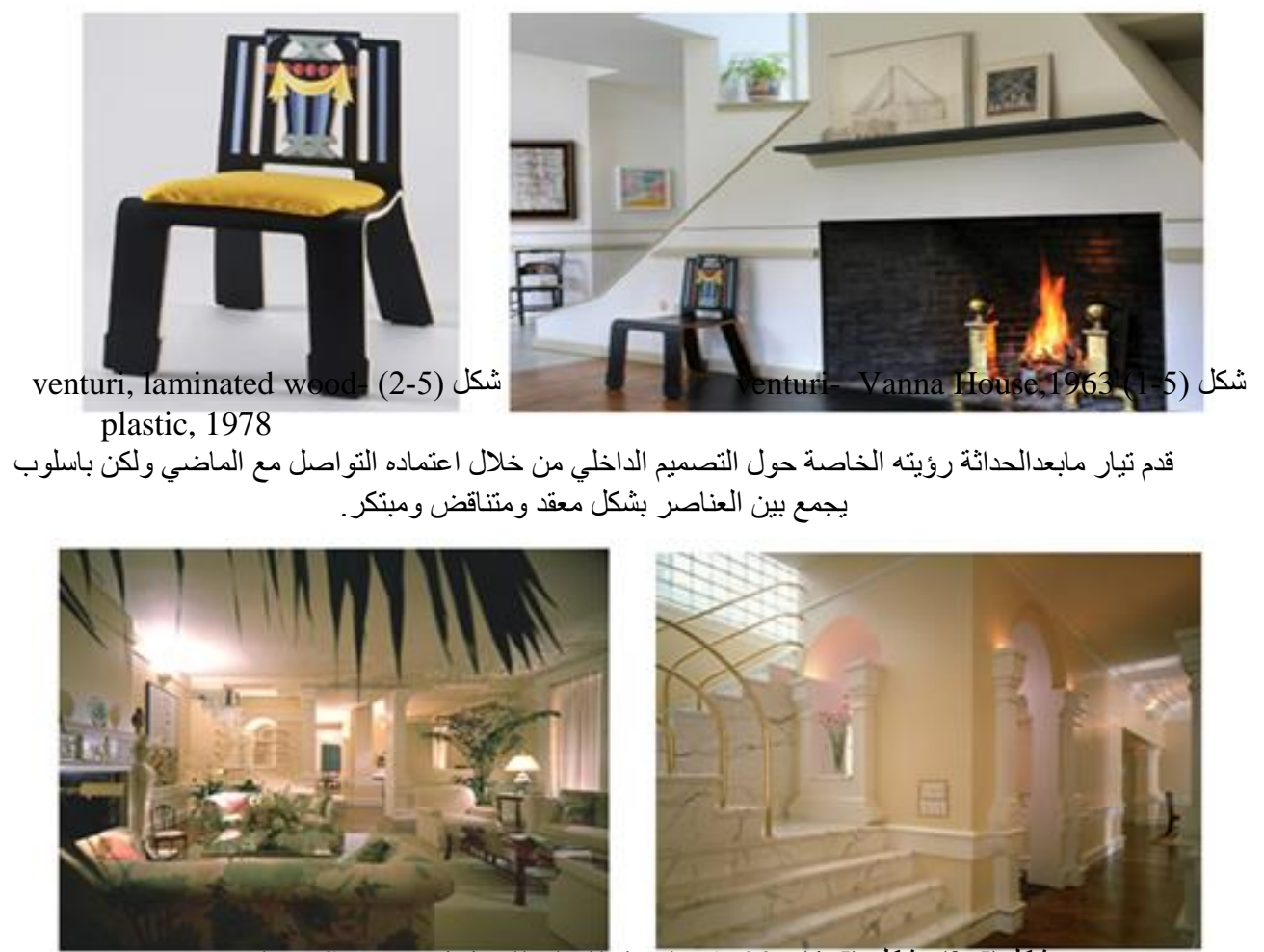

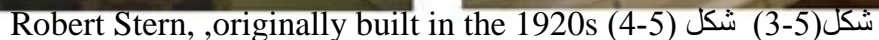

اعتمد ستيرن في تصميمه الداخلي على التحدث عن الأشياء الجديدة بلغة تقليدية مألوفة تضمن التواصل مع الآخر ، من خلال استخدام التفاصيل الكلاسيكية و التزيين.

لقد ظهرت خصوصية مفهوم التصميم الداخلي لما بعد الحداثة عبر ما طرحه ميشل كريفز Graves من تأكيد على تبنيه

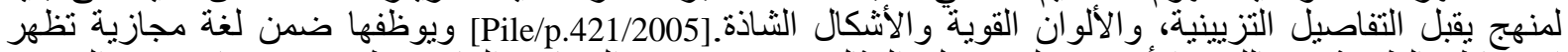

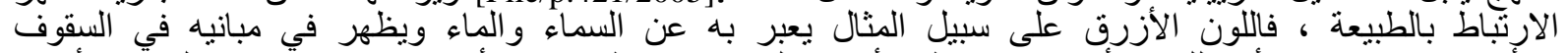

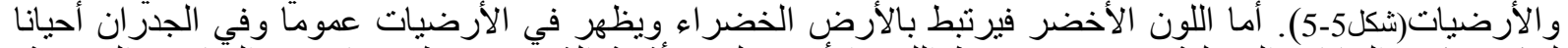

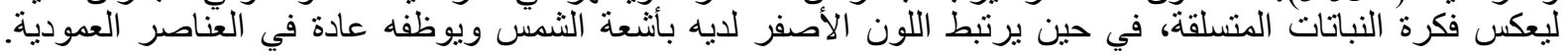

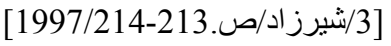

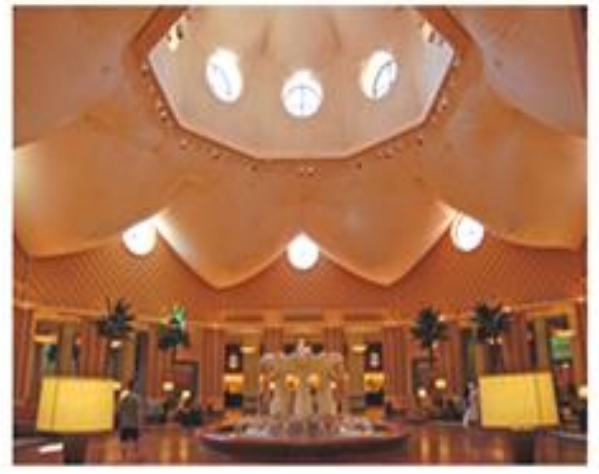

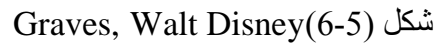

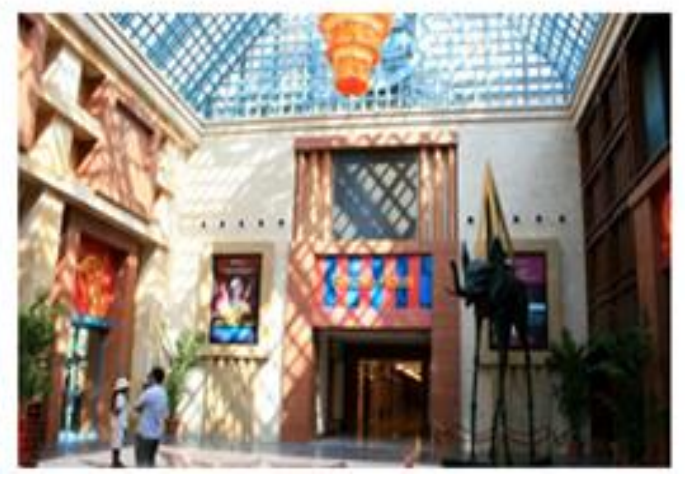

Graves, Sentosa HotelFestive(5-5) شكل أظهر كريقز ميله إلى إنخاذ من الكلاسيكية ومفهومه للطبيعة مرجعاً لتصاميمه الداخلية، إلى جانب الألو ان القوية و التزيين 
ويُظهر Graves في تصميمه الداخلي لفنادق ومبانى أدارة عالم دزني Walt Disney World تصميماً منو هجا

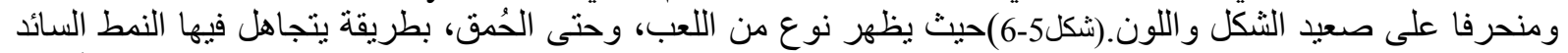

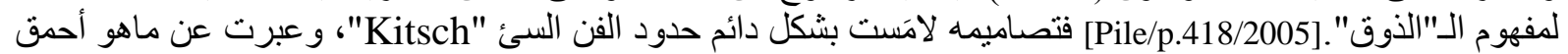

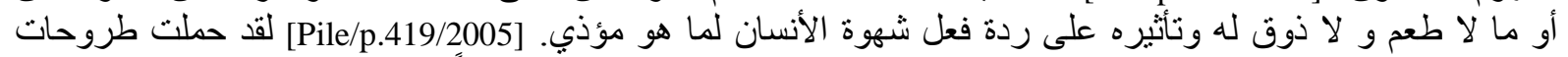

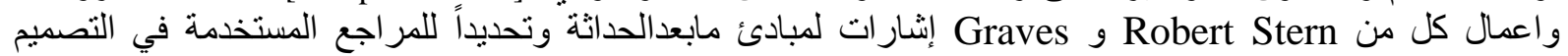
الداخلي إلى جانب إبراز عناصر التصميم الداخلي المؤثرة على توليد الهيئة الداخلية لعمارة مابعد الحداثة .

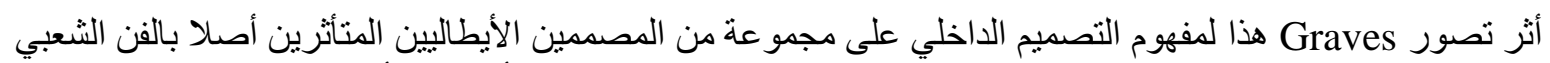

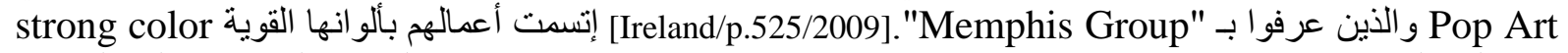
و اشكالها المدرجة Pile/p.420/2005].stepped form] قدمت مجموعة مدفس رؤيتها الغريبة المرنكزة على التصميم

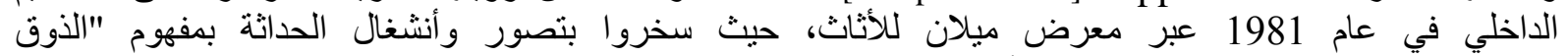

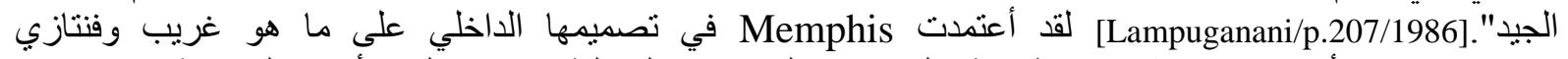

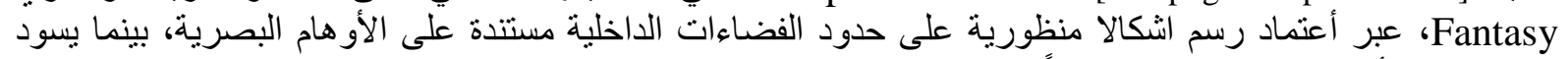

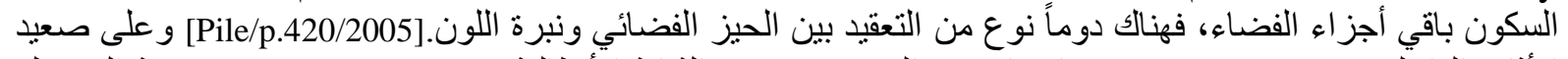

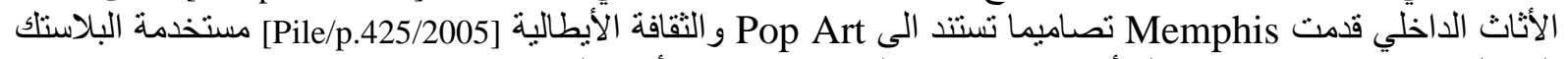

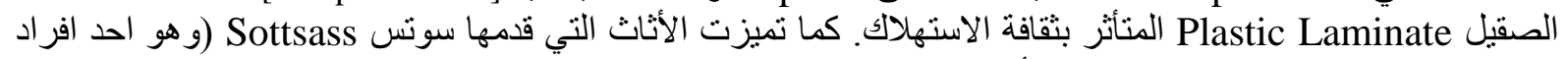

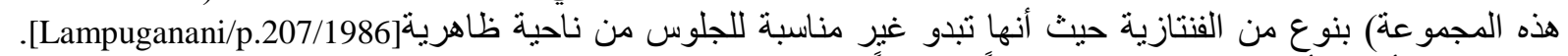

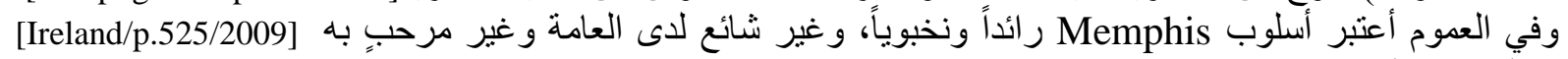

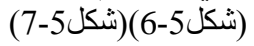

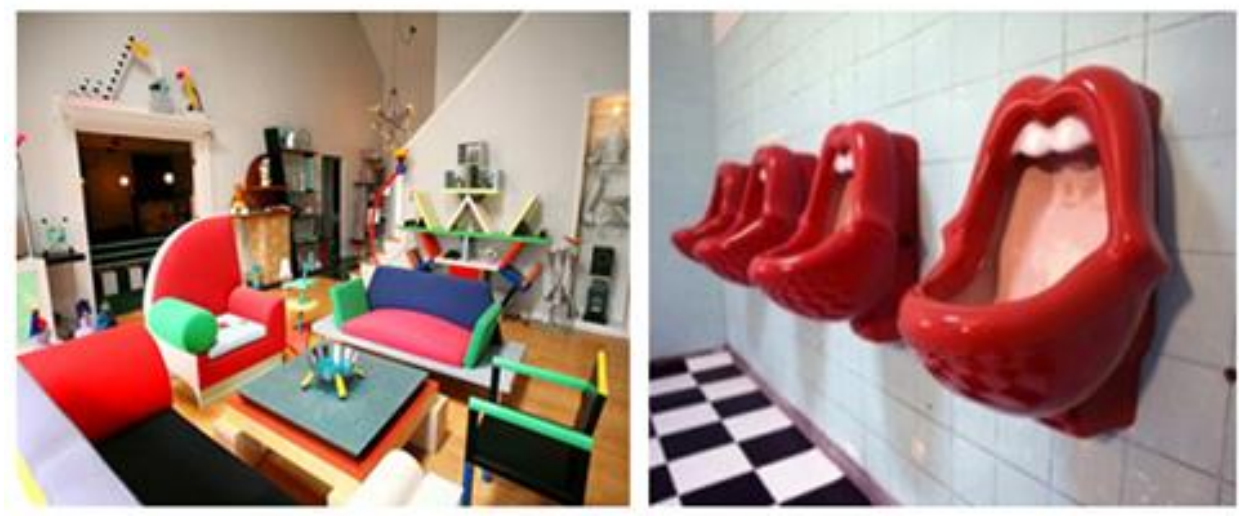

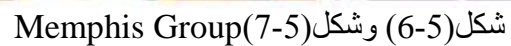

قدم تيار مابعدالحداثة تصاميم داخلية ذات طابع فنتازي تحمل في طياتها نوع من التهكم.

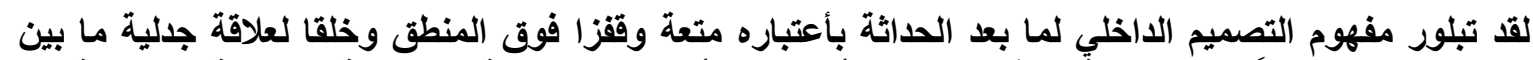

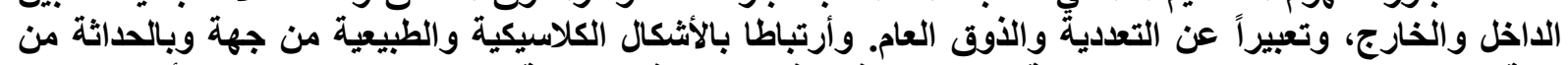

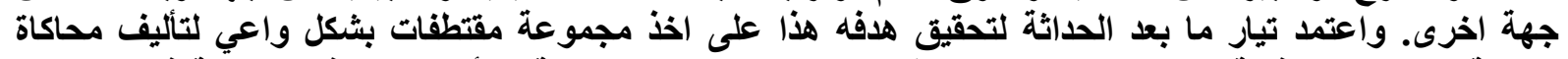

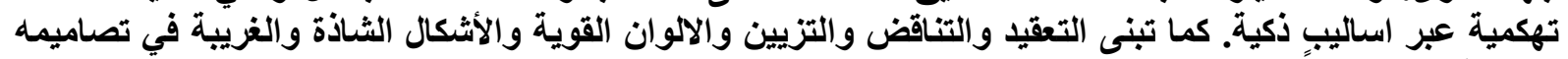

\section{6. أبرز الجوانب التي نوقش بصددها مفهوم التصميم الاخلي :}

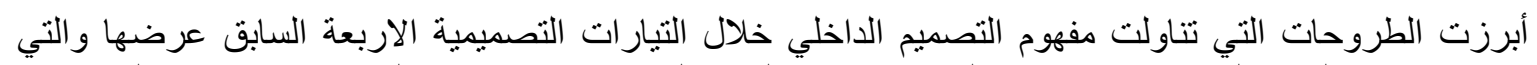

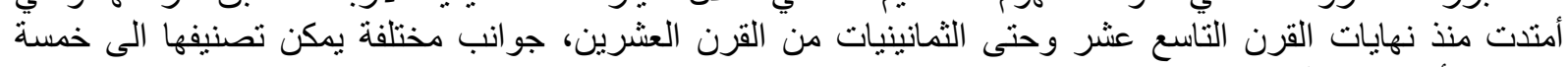

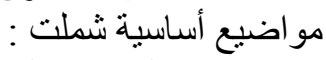

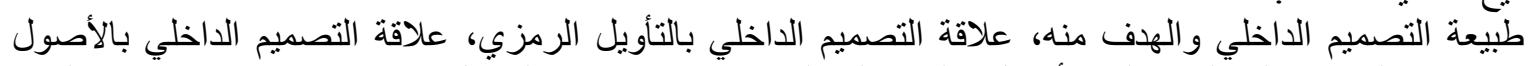

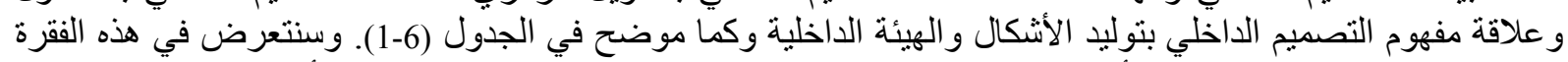

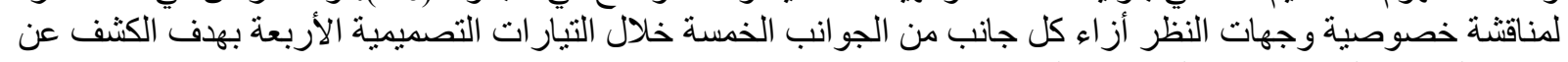

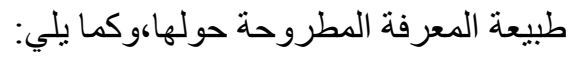




\subsection{1.بيعة التصميم الاخلي وجوهره :}

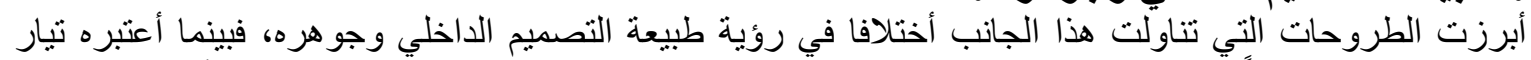

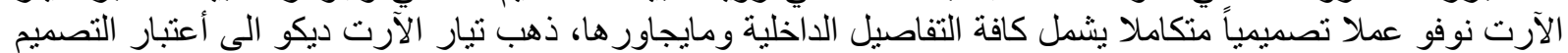

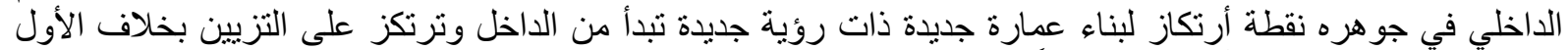

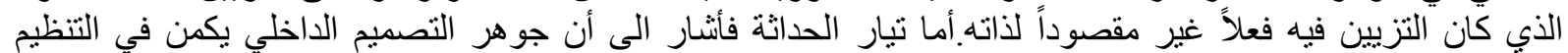

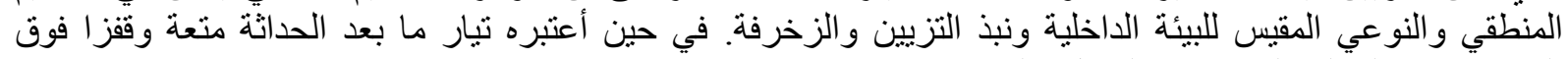

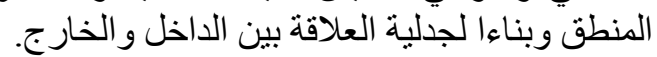

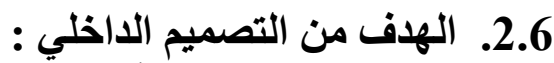

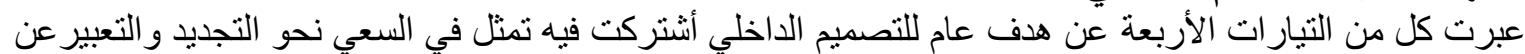

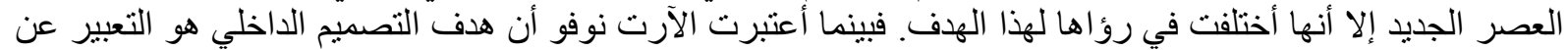

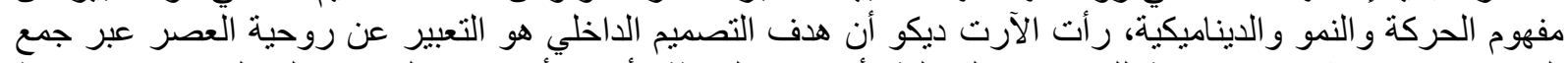

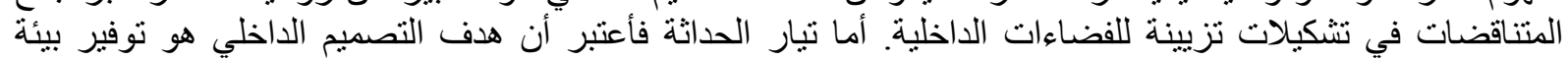

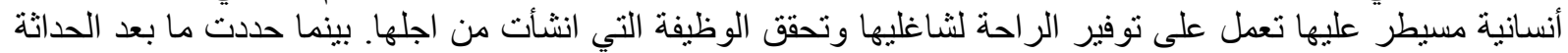

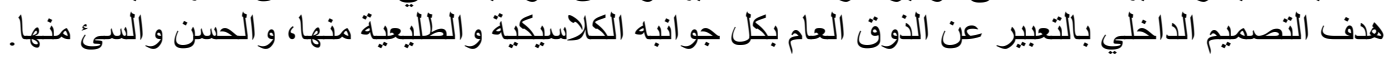

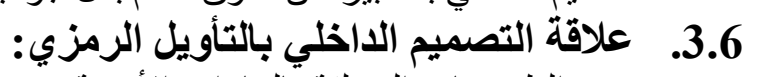

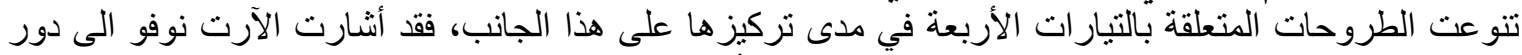

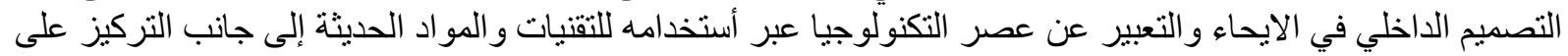

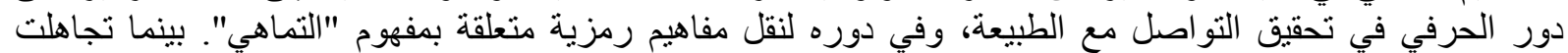

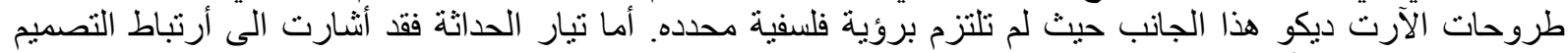

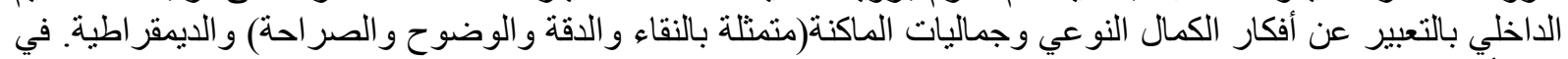

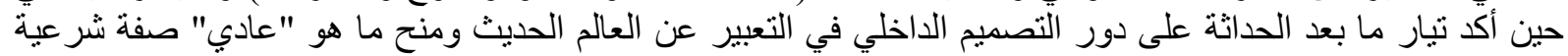

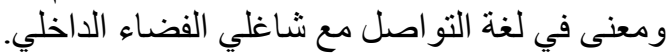
4.6

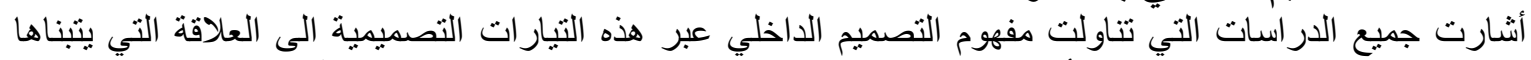

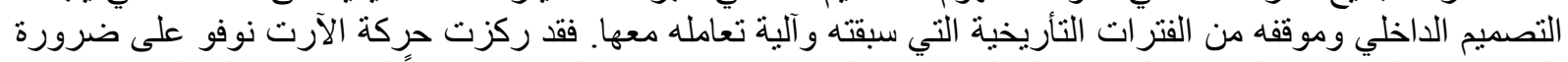

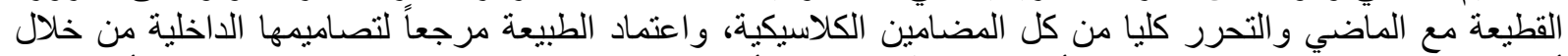

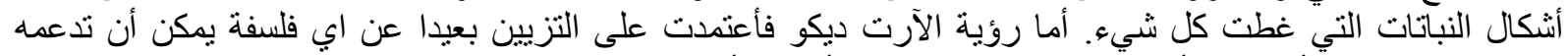

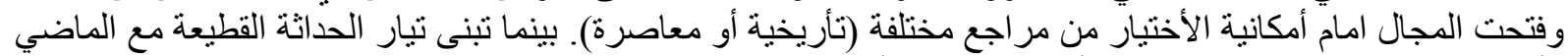

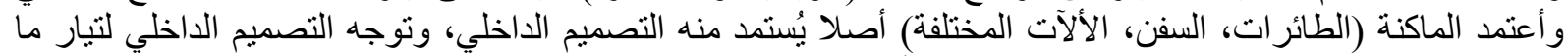

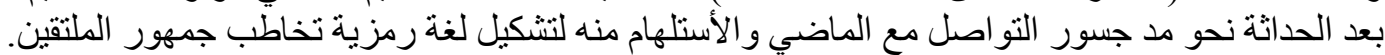
5.6.

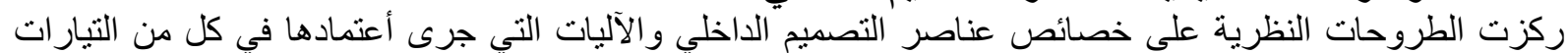

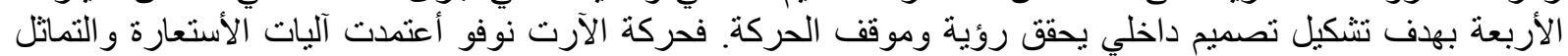

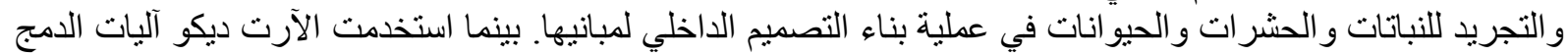

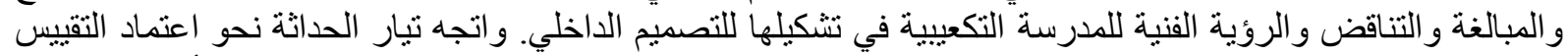

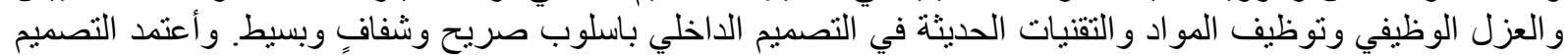

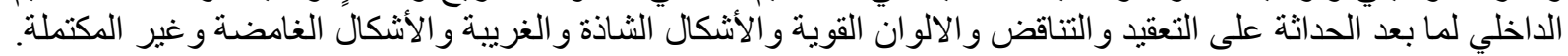

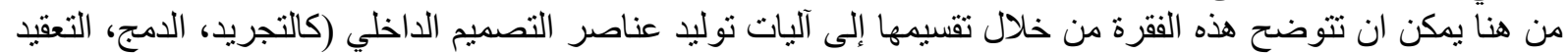

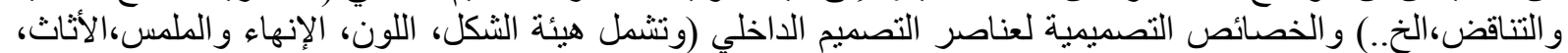


No. 4

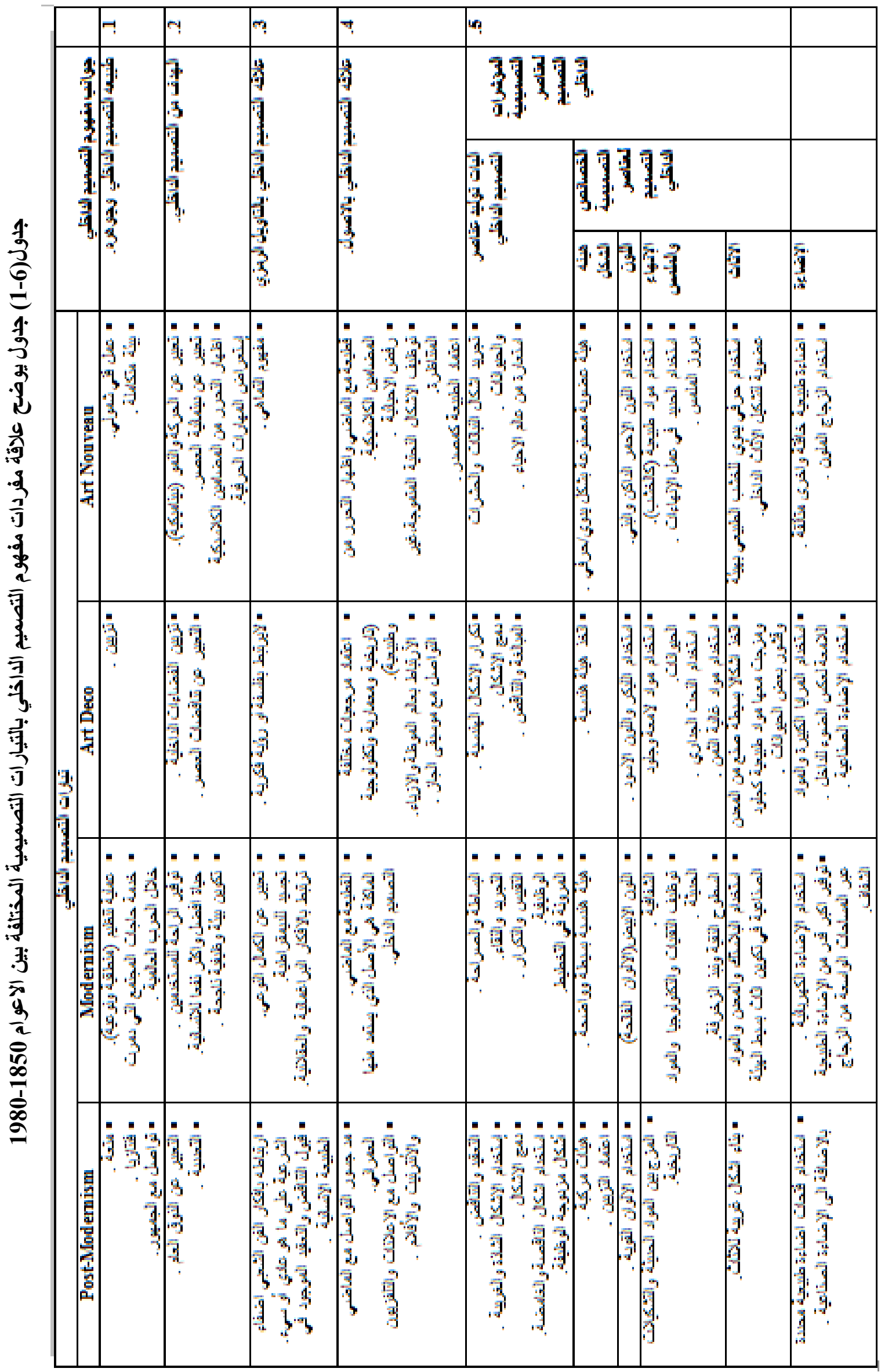


إنتقل البحث إلى المرحلة الثانية لحل المشكلة البحثية والمنمثلة بالتطبيق، من خلال انجاز دراسة عملية تتضمن اختيار

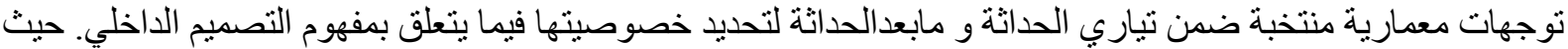

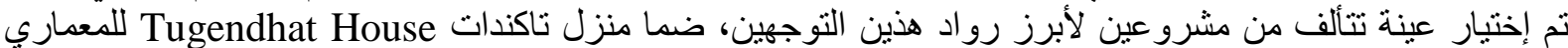

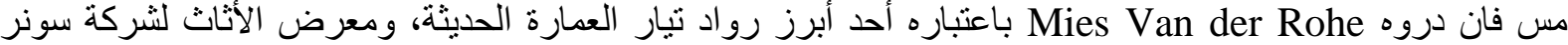
Sunar Furniture Showroom

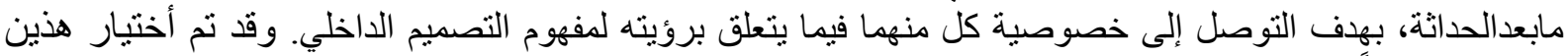

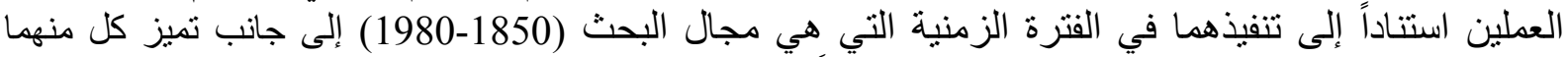
بصفتهما علامة دالة على التصميم الداخلي لكل تيار، فضلاً عن توفر الطئ الطروحات عنهما .

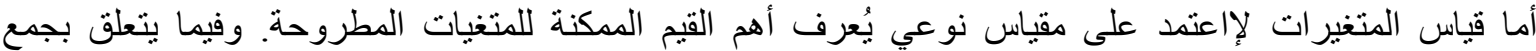

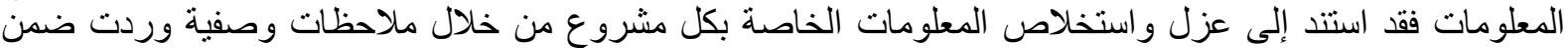

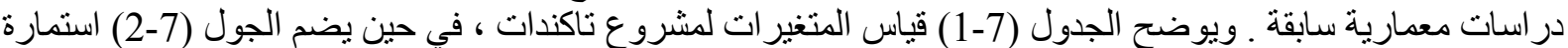

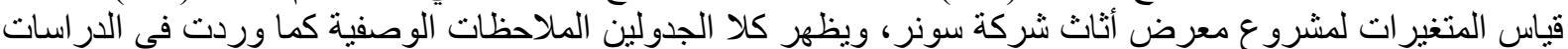
المعمارية أزاء كل من القيم قيد التطبيق .

جدول(1-7) جدول يوضح قياس المتغيرات لمشروع تاكندات Tugendhat .

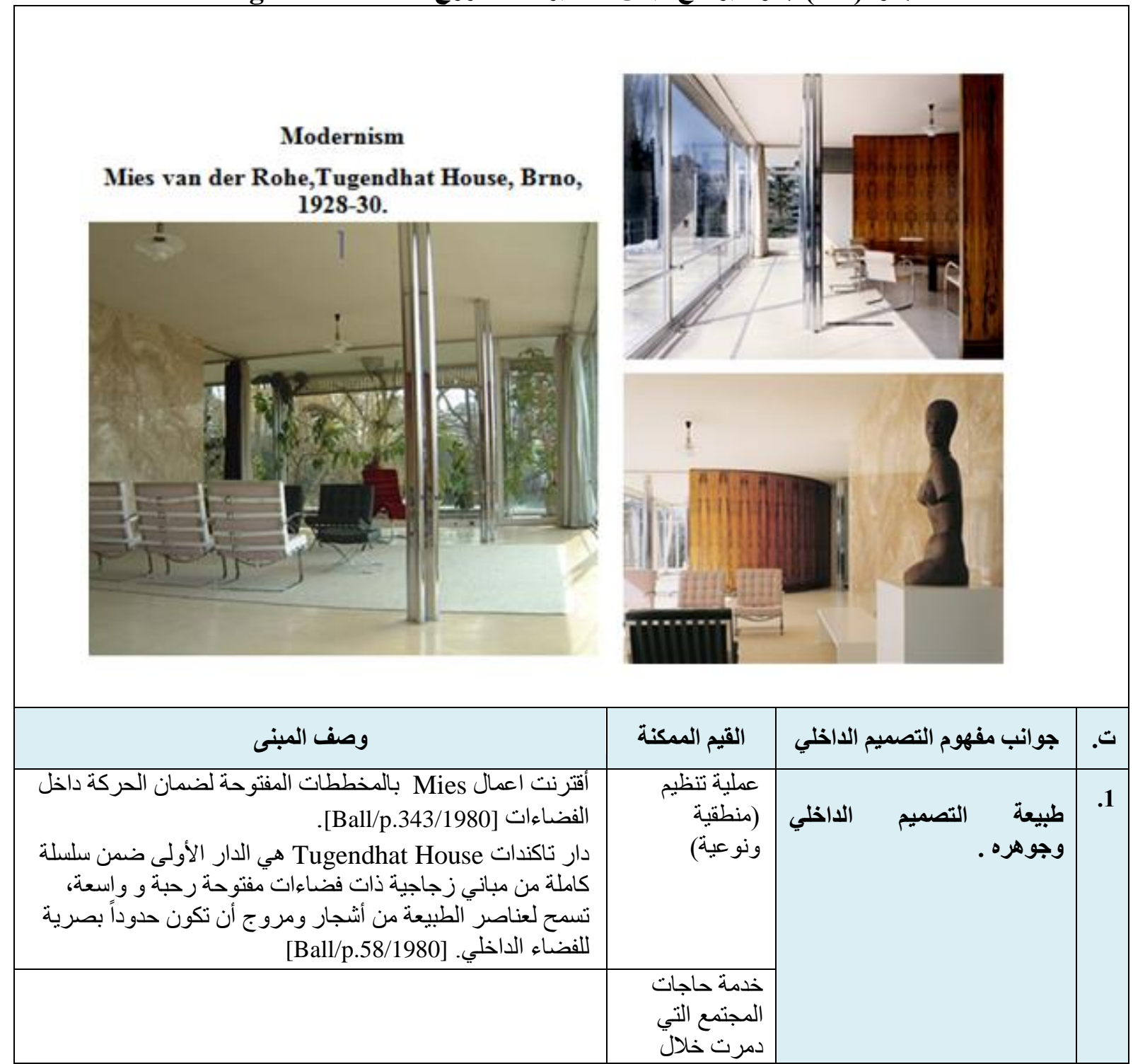




\begin{tabular}{|c|c|c|c|c|}
\hline & الحرب العالمية & & & \\
\hline 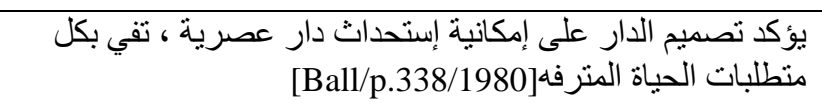 & 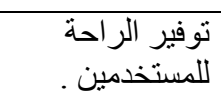 & \multirow{3}{*}{\multicolumn{2}{|c|}{ الهذف من التصميم الداخلي. }} & \multirow[t]{3}{*}{.2} \\
\hline 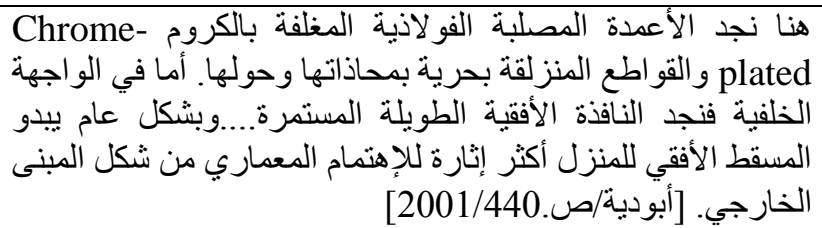 & نفعا للانسانية. افضل واكثر & & & \\
\hline \multirow[t]{3}{*}{ 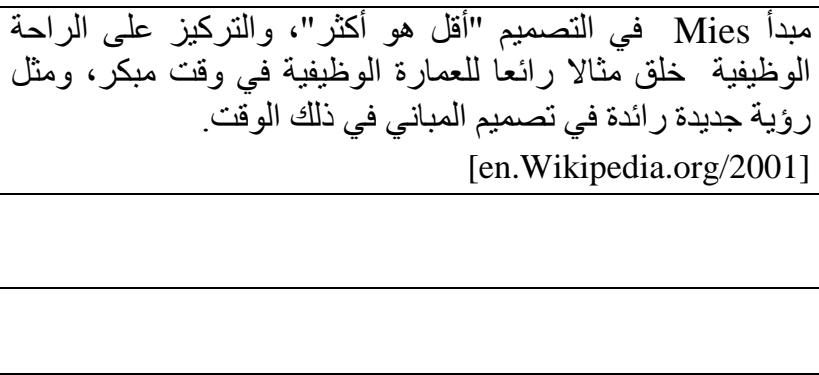 } & وظكوين بيئة & & & \\
\hline & ت تعبير عن الكمال & \multirow{3}{*}{\multicolumn{2}{|c|}{ الرمزية التصميم الداخلي بالتاويل }} & .3 \\
\hline & تلجسيد اطية. & & & \\
\hline فعالة [سنطاع Mies تحويل أو ترجمة العقلانية و التقييس الى معاني & والبر اغتبطاتية الافكار & & & \\
\hline & الماضيعة مع القعي & \multirow{2}{*}{ 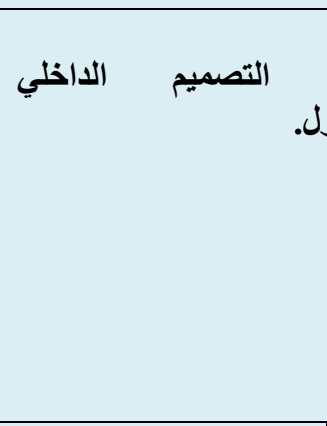 } & \multirow{2}{*}{ بالاصور } & .4 \\
\hline 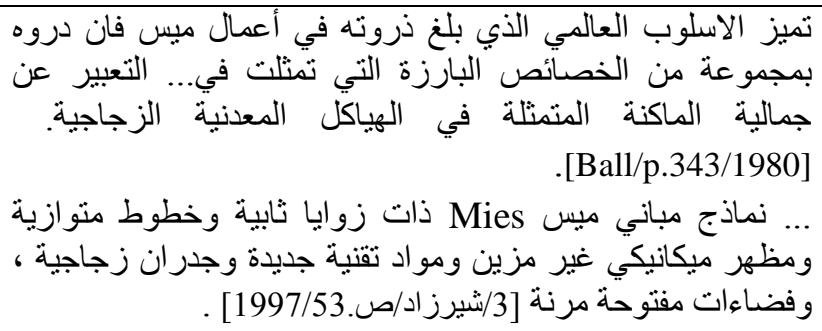 & 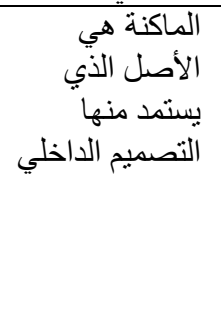 & & & \\
\hline 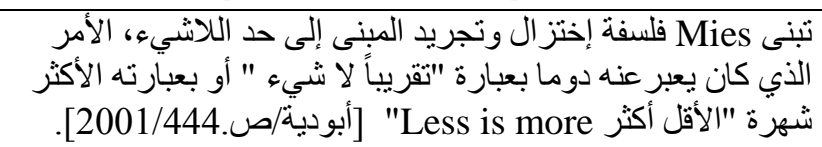 & والبساطة & \multirow[t]{7}{*}{ آلتصميم اللاخلي عناصر } & 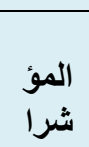 & .5 \\
\hline 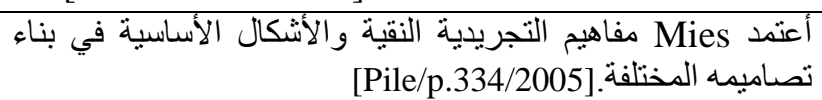 & التجريد و النقاء. & & 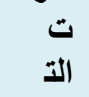 & \\
\hline 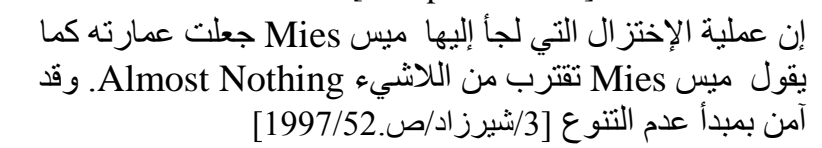 & & & لمية & \\
\hline & التقييس و التكر ار & & التر & \\
\hline & ألوظيفية. & & صد & \\
\hline 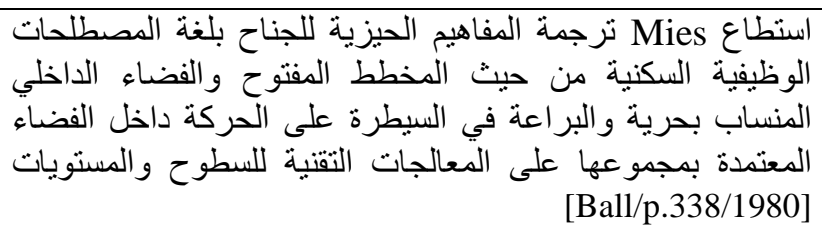 & التخطيط. في & & 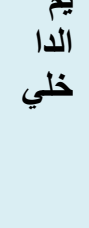 & \\
\hline 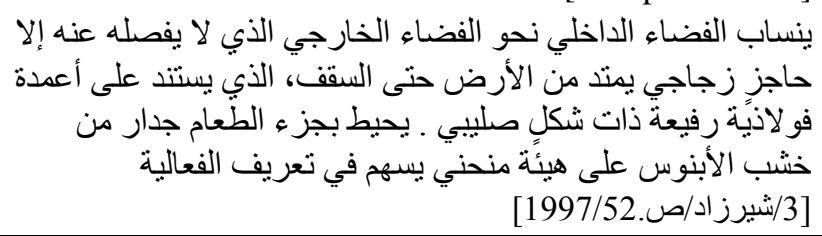 & & & & \\
\hline 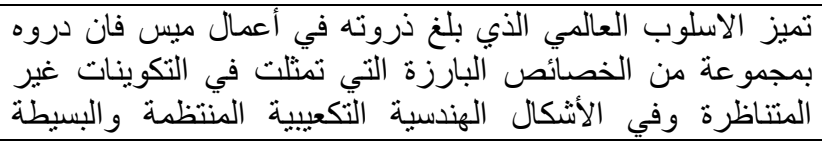 & بينية هندسية & هائَّة & & \\
\hline
\end{tabular}




\begin{tabular}{|c|c|c|c|}
\hline 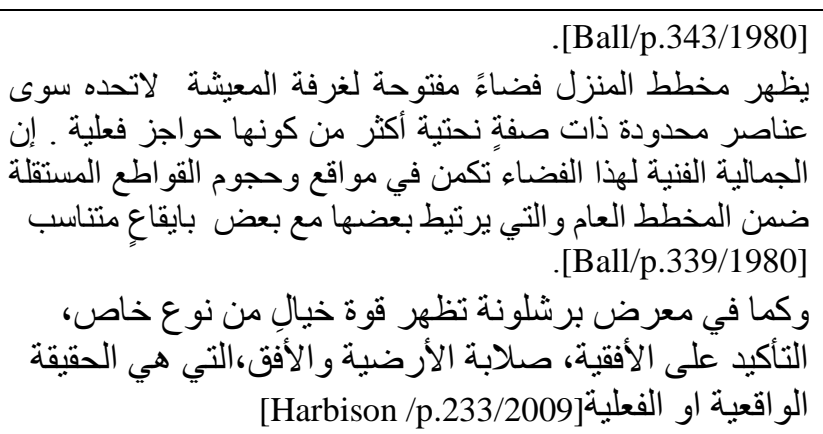 & & & التصاصريم التصيمية \\
\hline 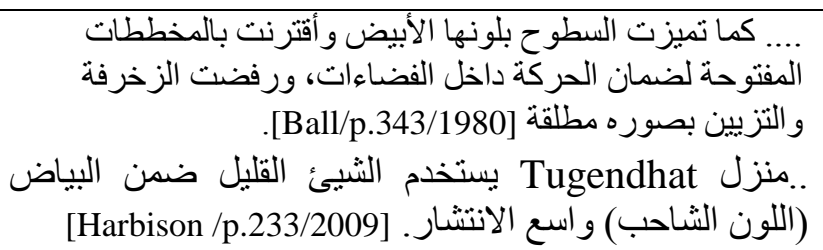 & (اللالون الابيضاتحة) & اللون & \\
\hline 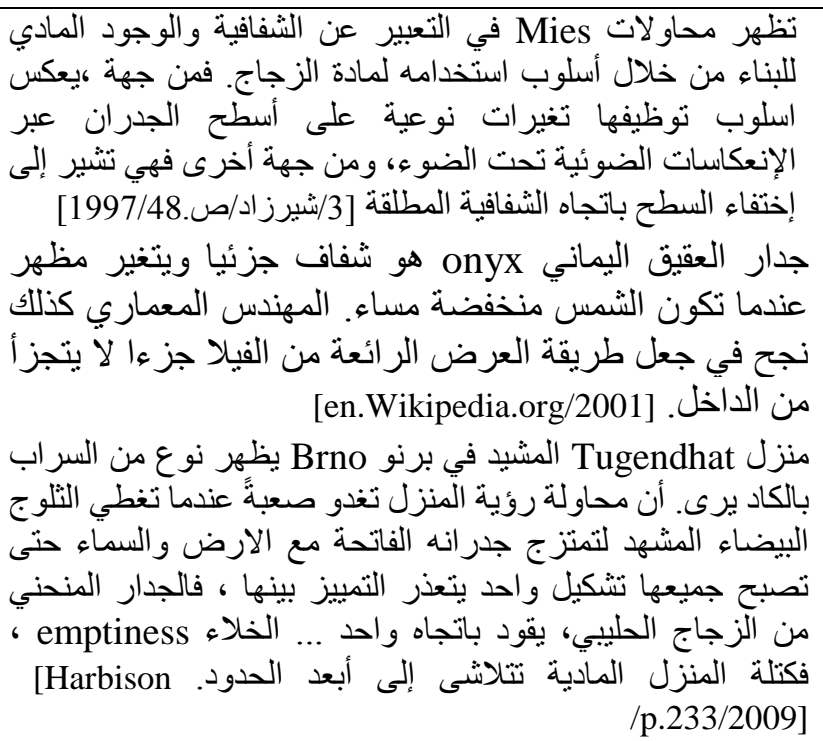 & الثفافية . & والإنهاء & \\
\hline 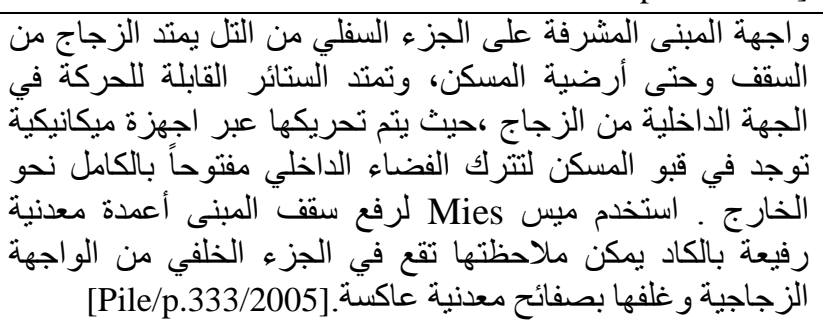 & و والتكنولو التقبيات & & \\
\hline 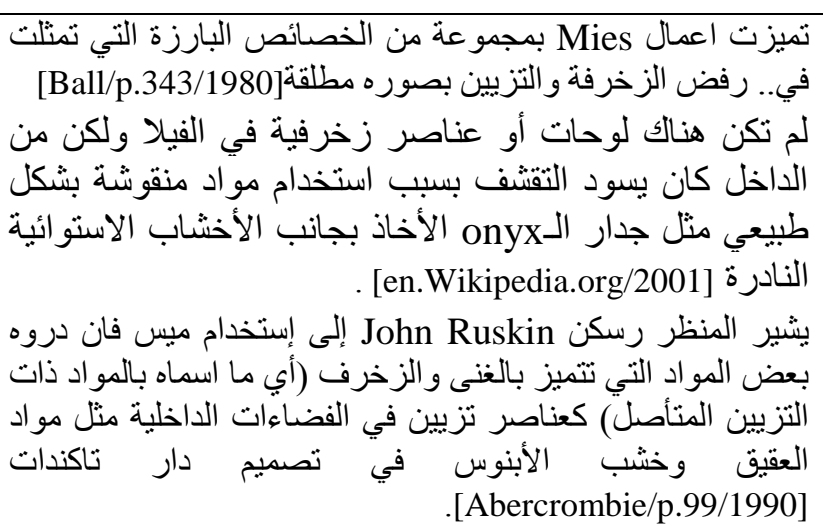 & ونبذ الزوحر النقة . & & \\
\hline 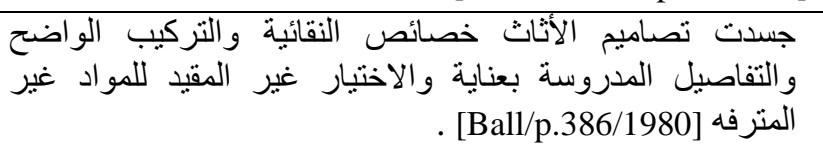 & والمتخدام والبلاستكاد & الأثثاث & \\
\hline
\end{tabular}


No. 4

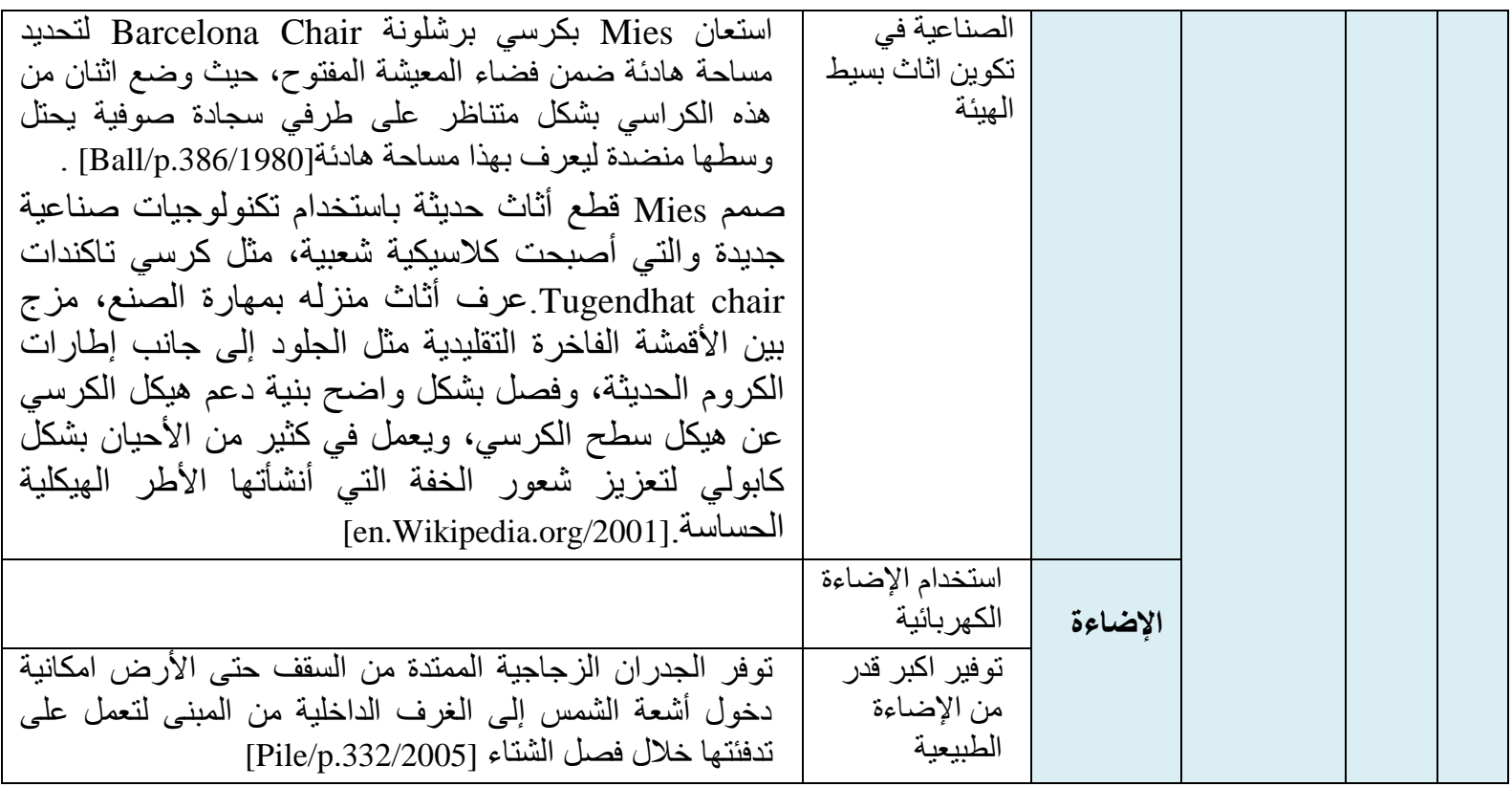

جدول(7-2) جدول يوضح قياس المتغيرات لمشروع سونر Sunar.

\section{Post-Modernism Michael Graves, Sunar Furniture Show room Los Angeles، California‘ 1980}
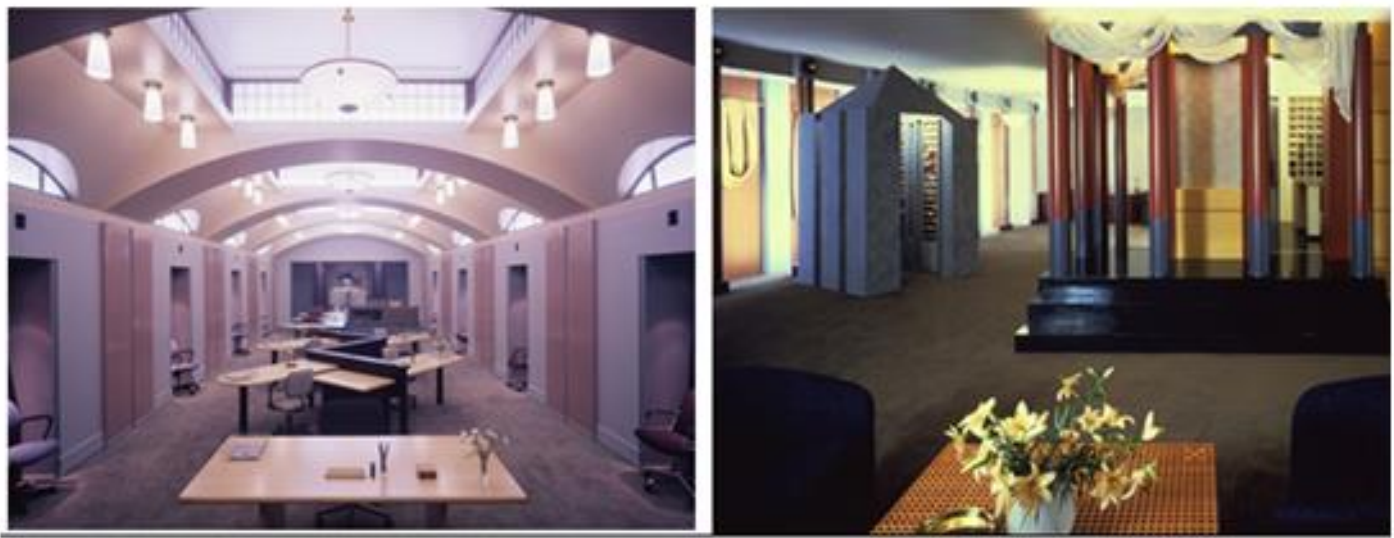

\begin{tabular}{|c|c|c|c|}
\hline وصف المبنى & القيم الممكنة & جوانب مفهوم التصميم الداخلي & ت ت \\
\hline 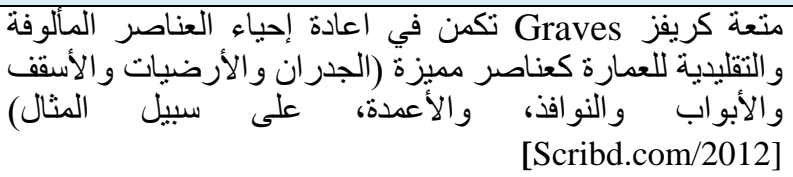 & متعة ، وفنتازيا & \multirow[t]{2}{*}{ طبيعة التصميم الداخلي وجوهره . } & \multirow[t]{2}{*}{.6} \\
\hline 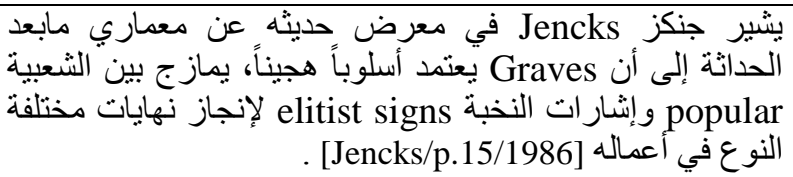 & الجمهور. & & \\
\hline 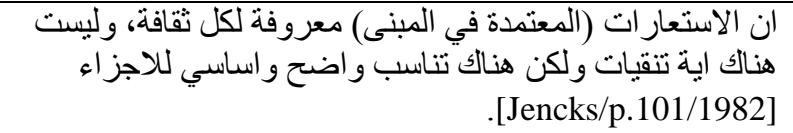 & الذوقبير العام & \multirow[t]{2}{*}{ الهذف من التصميم الداخلي. } & .7 \\
\hline & التعددية & & \\
\hline
\end{tabular}




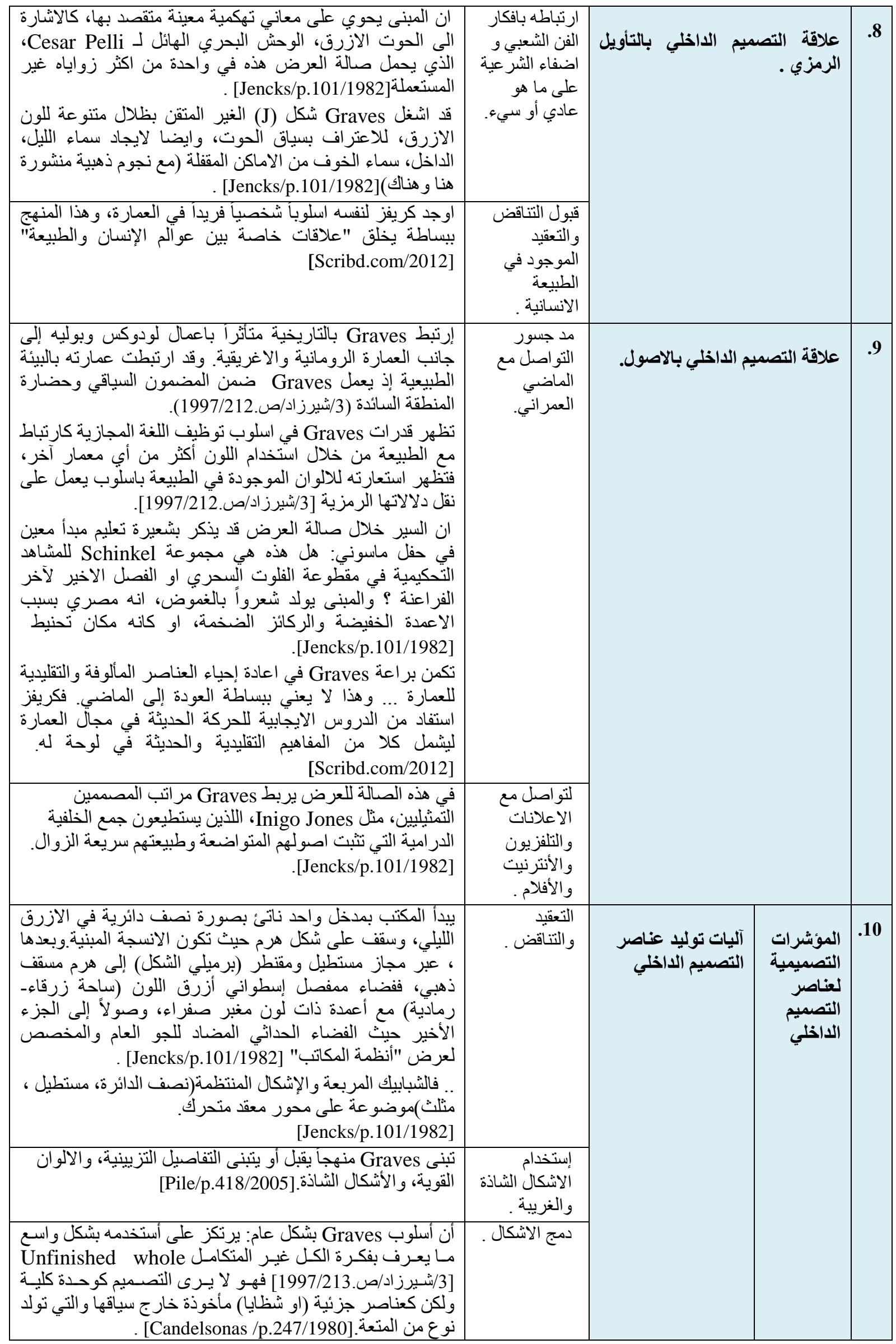




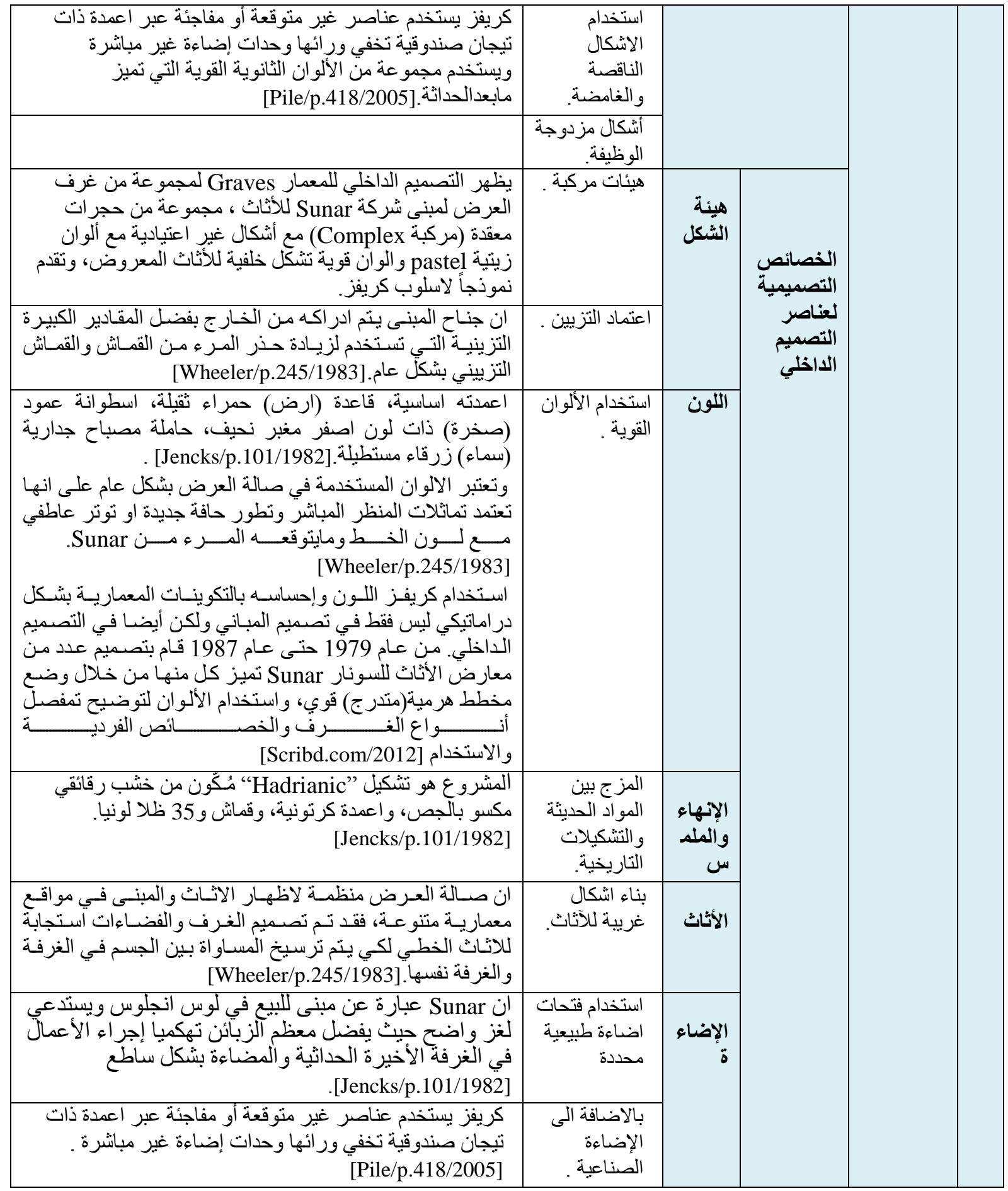

\section{1. مناقشة نتائج التطبيق (تحليد خصوصية مفهوم التصميم الداخلي في توجهات معمارية منتخبة):}

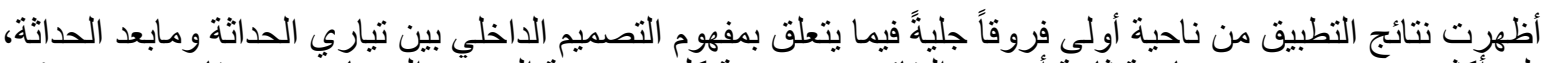

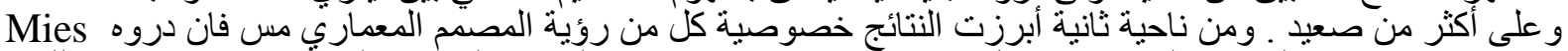

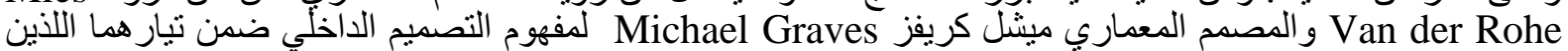
ينتميان إليه .

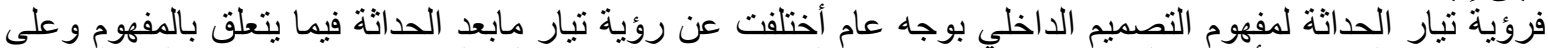

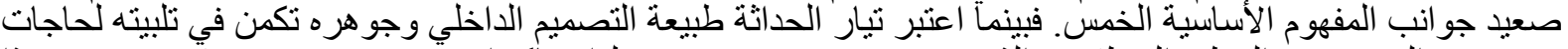

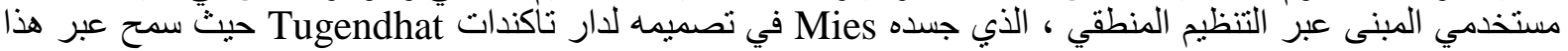




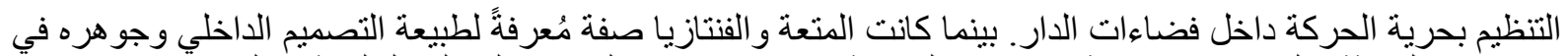

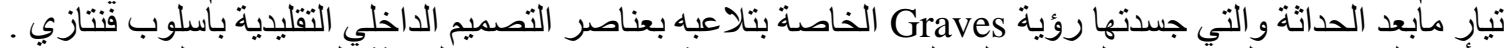

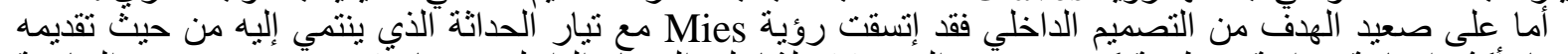

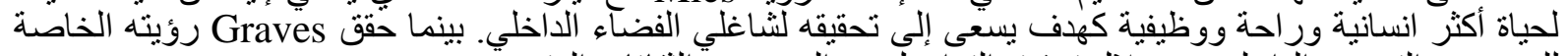

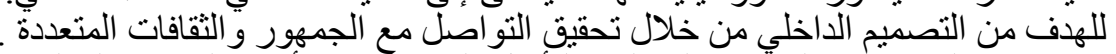

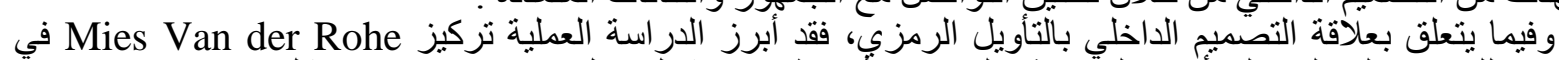

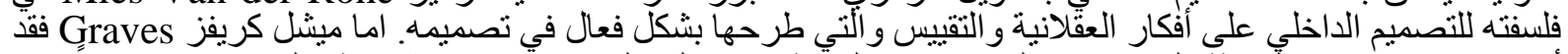

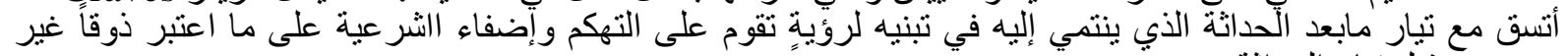

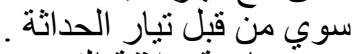

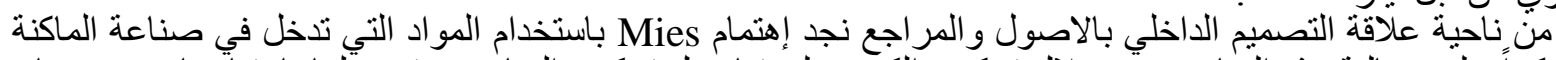

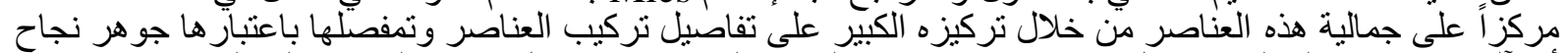

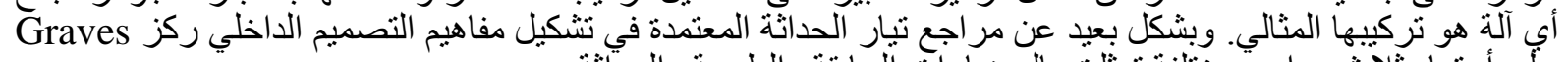

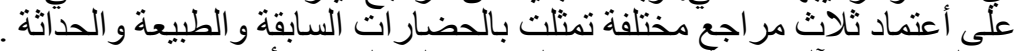

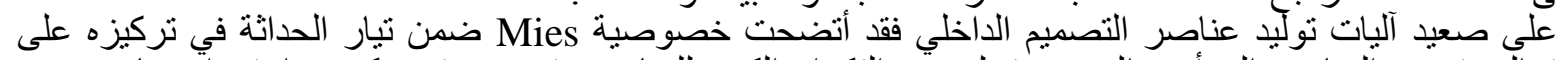

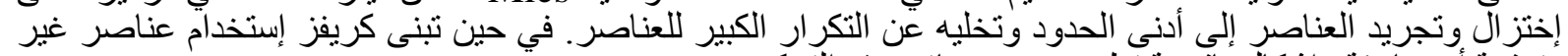

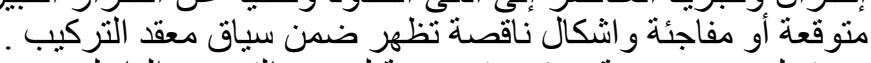

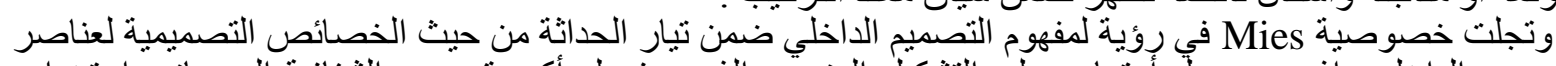

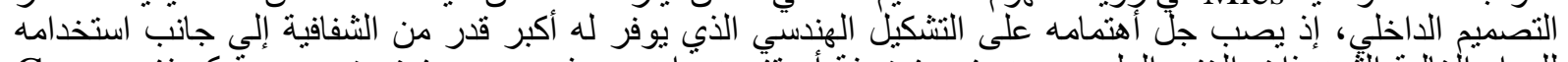

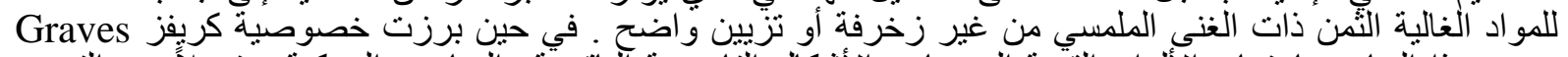

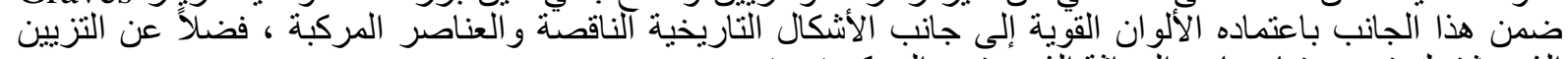

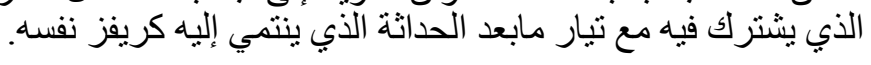

\section{2 : الإستنتاجات الخاصة بالتطبيق}

تقود نتائج التطبيق على دار Tugendhat لمعمار الحداثوي Mies Van der Rohe إلى استنتاج يقول بأن خصوصية

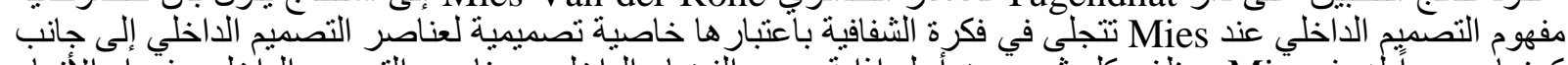

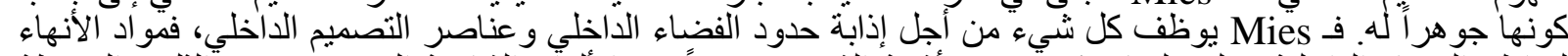

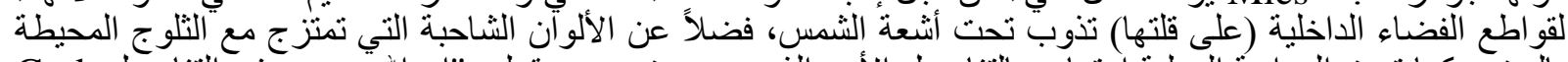

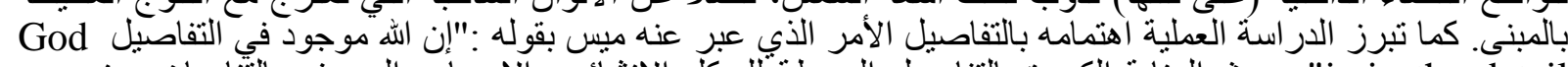

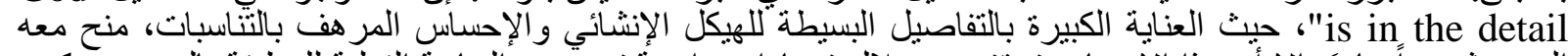

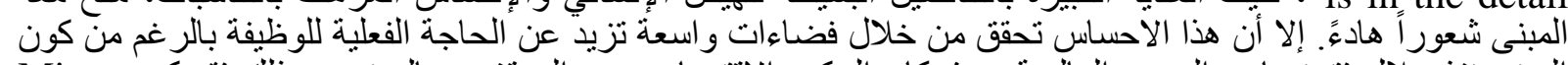

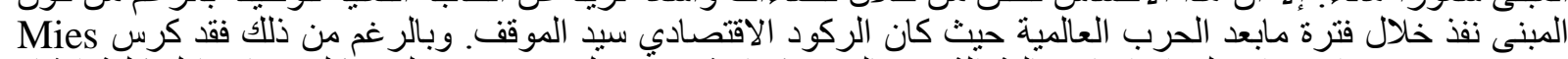

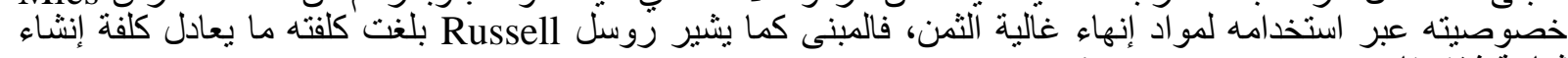

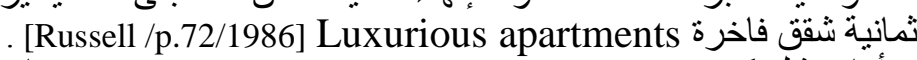

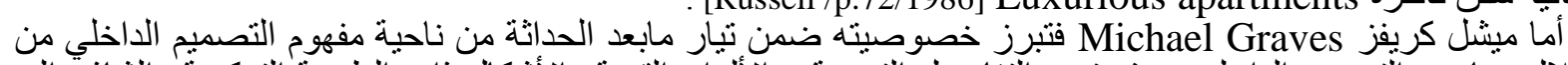

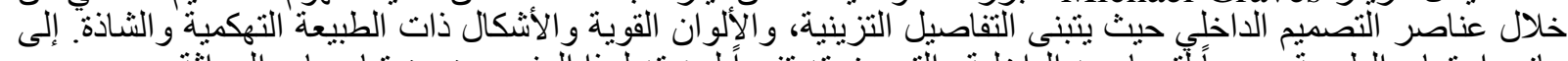

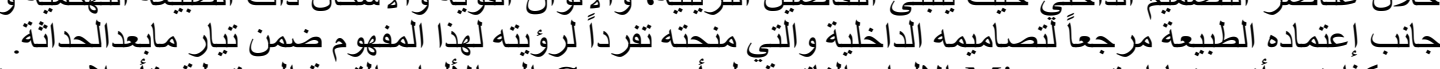

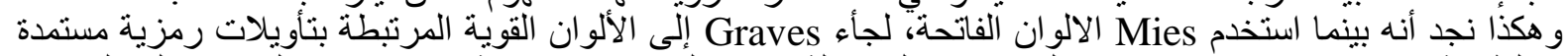

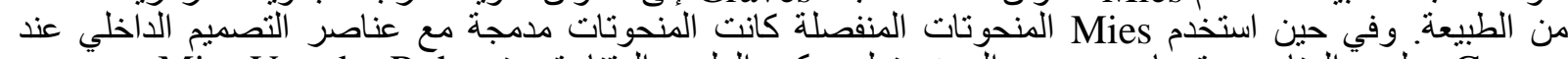

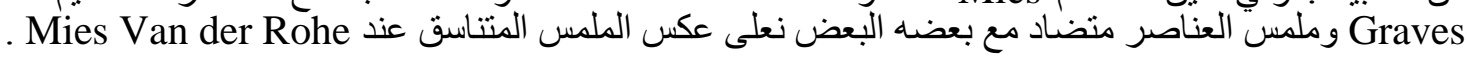

\section{8}

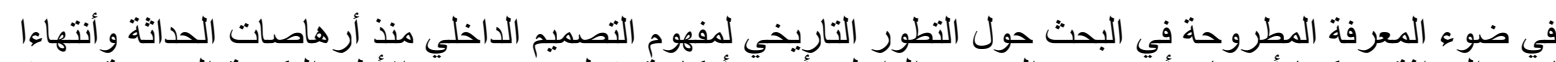

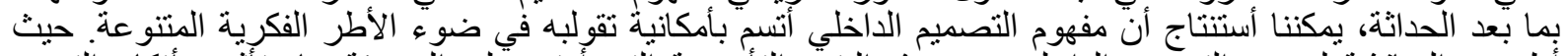

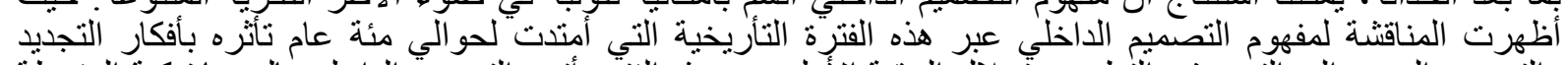

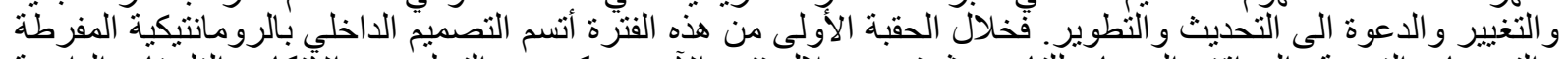

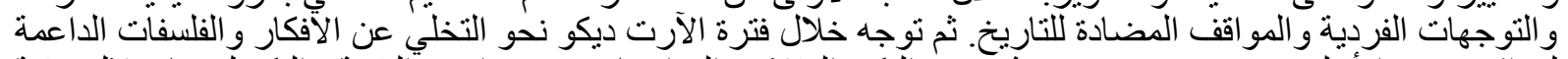

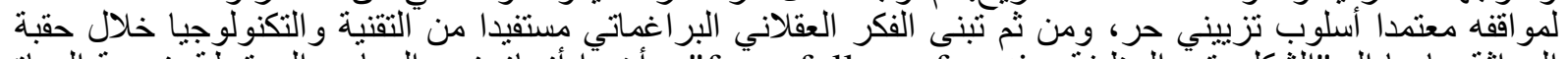

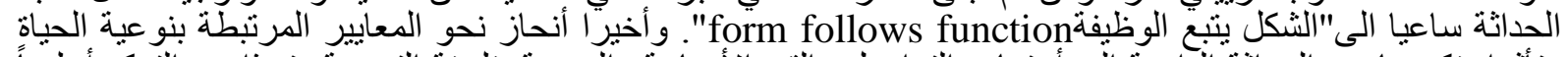

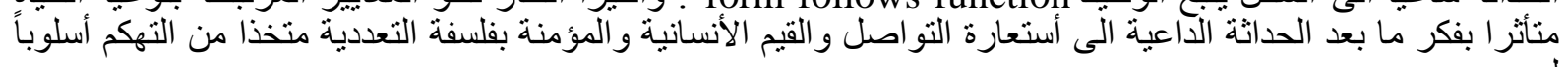

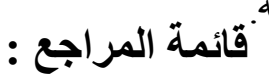

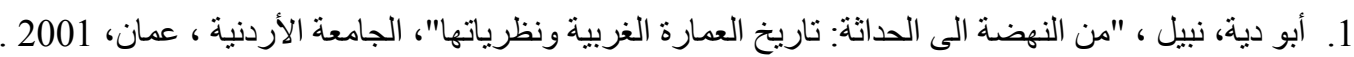

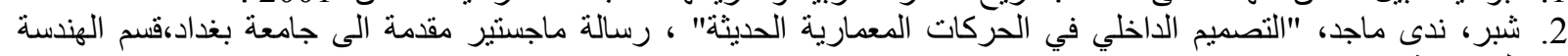


3. شيرز اد، شيرين احسان،"الأسلوب العالمي في العمارة بين المحافظة والتجديد"، دار الثؤون الثقافية العامة، بغداد، 1997.

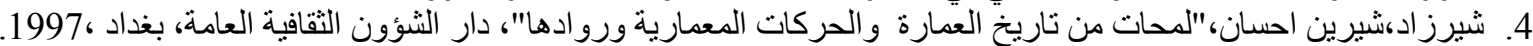

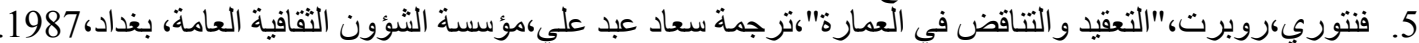

6. Abercrombie, Stanley, "A philosophy of Interior Design", Harper and Ron Publishers, New York.1990.

7. Ball, Victoria Kloss, “Architecture and Interior Design”, volume 2Johan Wily and Sons, New York, 1980.

8. Blake, Peter, "Mies Van der Rohe: Architecture and Structure", Penguin Books, England,1963.

9. Curtis, William j.r., "Modern Architecture since 1900", Prentice-Hall, Inc,London, 1983.

10. Gandelsonas , Mario," On Reading Architecture",in“Sings,Symbols and Architecture“, John Wiley and Sons -1980 .

11. Harbison ,Robert, "Travels in the History of architecture", Reaktion Book Ltd, London, 2009

12. Ireland, Jeannie, “History of Interior Design”, Fairchild Publications , Inc. , USA, 2009.

13. Janson , H.W., Anthony F. Janson, "History of Art", Rev. $6^{\text {th }}$ ed, Pearson Education, Italy , 2004.

14. Jencks , Charles ,“ Free Style Classicism”, A.D., No.1/12, Garden House Press , Great Britain ,1982.

15. Jencks, Charles, "what is post-Modernism”- Nortwestren University, Illiois, 1986.

16. Kilmer, Rosemary and W. Otie Kilmer, "Designing Interiors", Thomson Learning Inc., USA, 1992.

17. Kleiner, Fred and Christin J.Mamiya, "Garder's Art Through The Ages" $12^{\text {th }}$ edition, Thomson Learning Inc., USA, 2005.

18. Lampuganani,V.M., "Encyclopedia of 20th Century Architecture", Thames and Hudson Ltd., London, 1986.

19. Malanar, Joy Minico and Vodvarka, Frank,"The Interior Dimension : Atheoretical approach to enclosed space", Van Nostr and Reinhold, New York, 1992.

20. Massey, Anne, "Interior design of the 20th century", Thames and Hudson Ltd., London, 2001.

21. Pevsner, Nikolaus, "The Source of Modern Architecture and Design", Thames and Hudson Ltd., London, 1973.

22. Pile, John, "A History of Interior Design" ,Laurence King Publishing Ltd., second edition, United Kingdom, 2005

23. Russell, Frank, "Architectural Monographs : Mies van der Rohe European Works", Academy Edition,London, 1986.

24. Scribd, "Michael Graves", scribd.com/doc/58394089/Michael-Graves, Jun 2012 .

25. Wheeler,Karen Vogel \& Peter Arnell \& Ted Bickford,“ Michel Graves Building and Projects 1966-1981”- The Architectural Press LTD.- London- 1983.

26. Wikipedia, the free encyclopedia, "Villa Tugendhat", en.wikipedia.org/wiki/Tugendhat_House , Inscription 2001, 25 Jun 2012 .

27. http://www.greatbuildings.com/

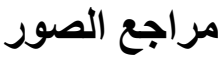

28. http://www.flickr.com/

$$
\text { تم اجراء البحث في كلية ألهنسة = جامعة ألموصل }
$$

